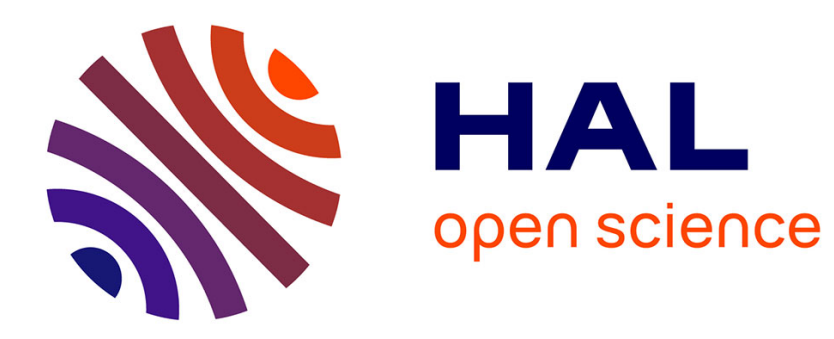

\title{
Syllable Reduction in Ye'kwana: Morphologized Phonology
}

Natalia Cáceres Arandia

\section{To cite this version:}

Natalia Cáceres Arandia. Syllable Reduction in Ye'kwana: Morphologized Phonology. International Journal of American Linguistics, 2018, 84 (2), pp.159-205. hal-03113481

\section{HAL Id: hal-03113481 \\ https://hal.science/hal-03113481}

Submitted on 1 Jun 2021

HAL is a multi-disciplinary open access archive for the deposit and dissemination of scientific research documents, whether they are published or not. The documents may come from teaching and research institutions in France or abroad, or from public or private research centers.
L'archive ouverte pluridisciplinaire HAL, est destinée au dépôt et à la diffusion de documents scientifiques de niveau recherche, publiés ou non, émanant des établissements d'enseignement et de recherche français ou étrangers, des laboratoires publics ou privés. 


\title{
SYLLABLE REDUCTION IN YE'KWANA: MORPHOLOGIZED PHONOLOGY ${ }^{1}$
}

\author{
Natalia Cáceres Arandia
}

UNIVERSITY OF OREGON

\begin{abstract}
In syllable reduction, the vowel of a nonfinal syllable deletes ( . . CV.CV . . .), resulting in the creation of a consonant cluster (. . C.CV . . .) where the first consonant of such a cluster can be said to be phonetically simplified with respect to the original consonant. Ye'kwana presents some unique features of syllable reduction: (i) attested thus far only at morpheme boundaries, alternation of reducing syllables occurs here within a single morpheme; (ii) reduction is conditioned by what could be analyzed as vowel initial suffixes. This latter phenomenon deviates from the patterns found in other Cariban languages and appears to violate explanations given in terms of syllable structure constraints. I discuss the problems in generating a synchronic phonological analysis to model the resultant apparent counterexamples, and then I demonstrate that this apparent violation is historically consistent with the overall pattern, but that a late sound change has eliminated the onset consonant from the suffix.
\end{abstract}

[Keywords: Cariban languages, historical phonology, sound change, vowel deletion, language description]

1. Introduction. Gildea (1995) describes Cariban syllable reduction as the deletion of an unstable vowel in a final CV syllable before a -CV suffix, which in turn creates a consonant cluster-by making the former onset of the final syllable a coda to the preceding syllable - that simplifies along different pathways in different languages. The first mention of the pattern in the family dates back to Adam (1893) and the first description of the phenomenon in a language was made for Kari'nja (Hoff 1968). At the time it was also discussed in a comparative perspective as a phenomenon that

\footnotetext{
${ }^{1}$ I gratefully acknowledge the Ye'kwana people for the time they made available in helping me with the description of their language. Many thanks too to Spike Gildea and Gérard Philippson for their valuable comments on an earlier version of this paper. This paper has benefited also from the review process. I thank Sérgio Meira, who was an obvious and confirmed reviewer of this paper, for providing several important suggestions. I am also grateful for the anonymous comments provided by a second reviewer and the editors. Special thanks to Yajödeniwa Zuleima Jiménez Velásquez for making recordings of herself to illustrate most of the examples in the paper (available online at at www.journals.uchicago.edu/doi/full/10.1086/696196; "wav" file names are keyed to example numbers). Any remaining errors are entirely my own. Fieldwork research leading to this paper has received funding from the CNRS project AALLED (ANR06-CNRS-0022), the ELDP (FTG0159), the Agence Universitaire de Francophonie, the Institut des Amériques, the Fyssen Foundation and the LabEx ASLAN (ANR-10-LABX-0081). I also acknowledge support from the NSF (BCS-1500714) during revisions.
}

[IJAL, vol. 84, no. 2, April 2018, pp. 159-205]

(C) 2018 by The University of Chicago. All rights reserved.

0020-7071/2017/8304-0002\$10.00 DOI 10.1086/696196 


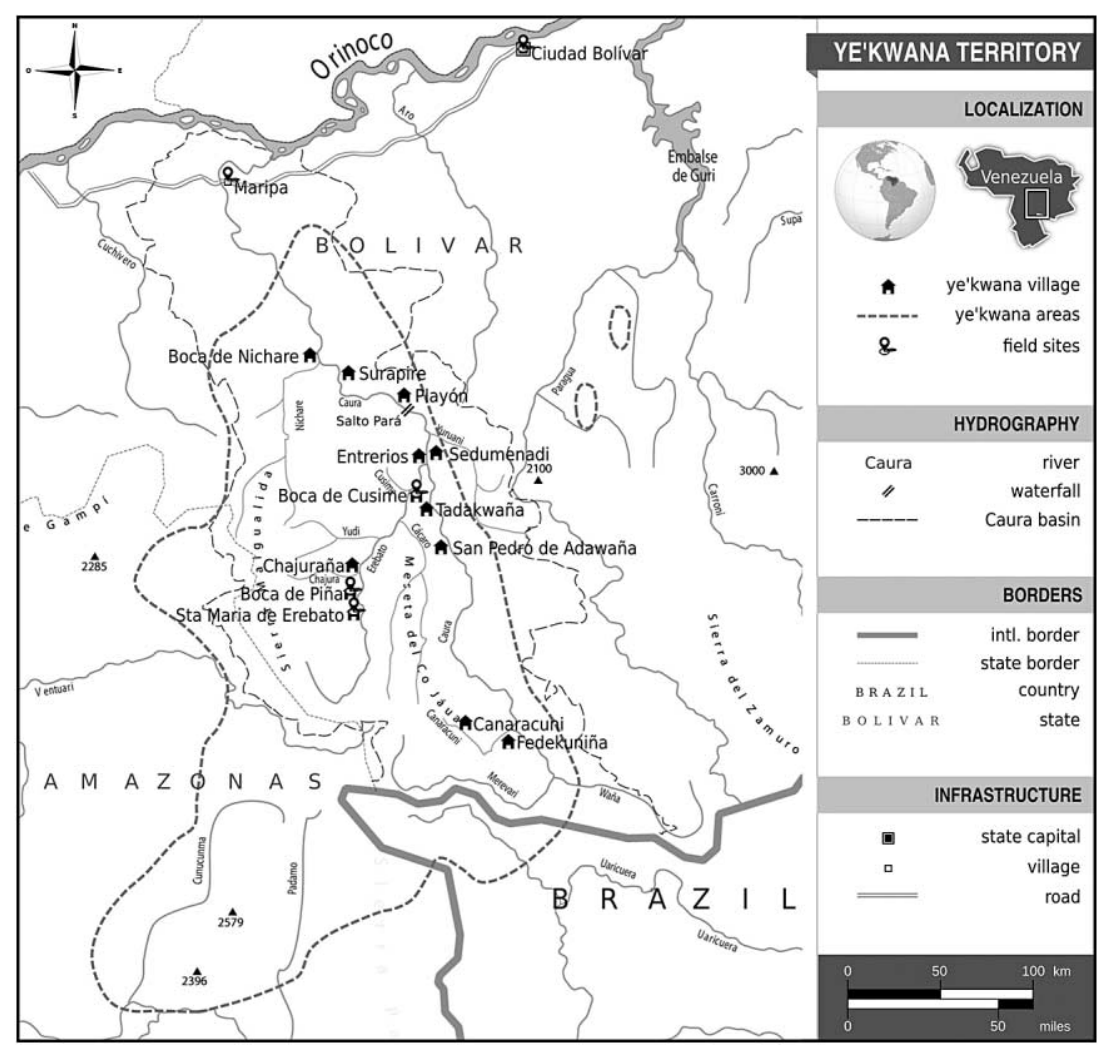

Fig. 1-Ye'kwana villages in the Caura Basin. Map design by Mathieu Wostyn.

complicated identification of cognates (Girard 1971) and only later labeled as syllable reduction (Mattei Muller 1981). Gildea (2012:449) reports that examples of syllable reduction have been found in nearly all the languages of the family, including three patterns not attested in his first account of the phenomenon. Specific studies of the phenomenon have stressed the regularity and predictability of syllable reduction, but some of the patterns found in Ye'kwana (mch), a Cariban language spoken in Venezuela and Brazil (figure 1), ${ }^{2}$ show there is a lot about it that is unpredictable. Two of those patterns-reduction with vowel-initial suffixes and alternating reducing syllables_-present previously undescribed features and, remarkably, contradict

\footnotetext{
${ }^{2}$ There are nearly 9,000 Ye'kwana speakers. They live for the most part in traditional villages in the tropical forest accessible only by river or air. This paper is based on a corpus of firsthand data collected for documentation and grammatical description between 2006 and 2014 among speakers along the Erebato River of the Caura Basin in southern Venezuela.
} 
(1a)

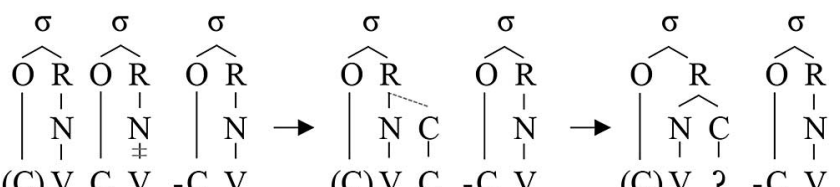

(C) $\mathrm{V} C \mathrm{C}-\mathrm{C} \mathrm{V}$

(C) V C - C V

(C) $\mathrm{V} ?-\mathrm{C} \mathrm{V}$

(1b)

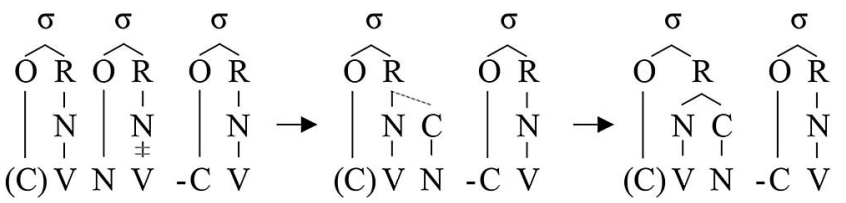

FIG. 2-General pattern of syllable reduction.

regularities observed on the basis of the other languages of the family. This paper shows that, although synchronically other patterns of syllable reduction exhibit phonemic regularities, a purely synchronic phonemic analysis fails to predict the occurrence of certain consonantal segments or features in these two newly found patterns of Ye'kwana. In contrast, these patterns can be satisfactorily accounted for with a diachronic analysis that partially follows from knowledge of comparative facts.

The most general pattern of syllable reduction, which has been described in most languages of the family and is also present in Ye'kwana, can be illustrated as in figure 2. The input forms (on the left) are a bisyllabic (C)VCV root plus a-CV suffix; the first step is the deletion of the vowel from the last syllable of the stem, which leads to the creation of a heterosyllabic consonant cluster at the affix boundary. The first consonant of this cluster then neutralizes to / $/$ / (for obstruents in (1a)) or to a homorganic nasal $\mathrm{N}$ (for nasal stops in (1b)): schematically $\mathrm{C}_{\text {[-nasal] }} \mathrm{V} \rightarrow$ ? / $\mathrm{CV} \_-\mathrm{CV}$ and $\mathrm{C}_{[+ \text {nasal] }} \mathrm{V} \rightarrow \mathrm{N} /$ $\mathrm{CV} \_\ldots-\mathrm{CV}$ ). The overall term "syllable reduction" reflects the fact that loss of the nucleus vowel of the second syllable leads to a change in syllable structure, in this case from tri- to bisyllabic.

I illustrate the morphological structure of the verb word in Ye'kwana with a non-reducing stem, emakura 'rot' (in bold face in 2a-c). In these examples, the root has the same number of syllables in every surface form. ${ }^{3}$

\footnotetext{
${ }^{3}$ Examples begin with a line showing the phonetic form in IPA—including prosodic information, such as iambic vowel lengthening - and syllable segmentation. The second line provides morphological boundaries and a unified representation of each morpheme: these forms can be interpreted as underlying representations, internally reconstructed forms, or convenient uniform representations of each of the morphemes of the language. Abbreviations used include
} 


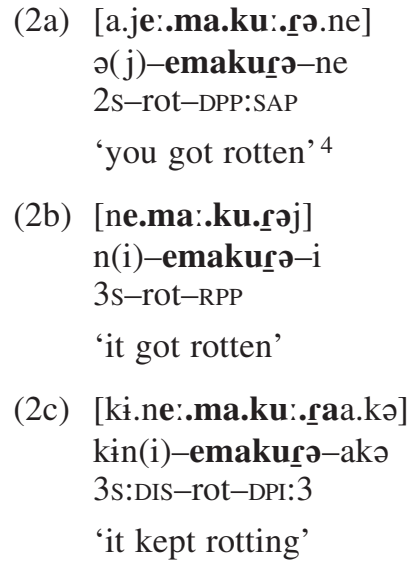

The primary differences in the stem between the form suffixed with -ne in (2a), the form suffixed with $-i$ in (2b), and the one with -aks in (2c) involve vowel duration: in a pattern common to several Cariban languages, rhythmic stress (discussed in 2.2.1) lengthens the vowel of every light syllable heading an iambic foot. A secondary difference is the assimilation of the final vowel of the verb stem /ə/ to the initial vowel /a/ of the suffix -aka in (2c).

Now consider the equivalent conjugated forms for a reducing stem: for the root akata 'cut', the form with the suffix $-i(3 b)$ presents the same three syllables as the unified form, [a.kə.tə], but the phonetic form with the suffixes -ne (3a) and -akə (3c) contains only the two syllables [a.kə?]. In these cases, we argue that the final syllable /tə/ has undergone syllable reduction, which allows us to categorize /akətə/ as a reducing stem.

the following: 1 = first person, 2 = second person, 3 = third person, $($ slash $) /=$ "acting on", $\mathrm{A}=$ agent of transitive verb, $\mathrm{ABS}=$ absolutive, $\mathrm{AZR}=$ adverbializer, $\mathrm{CAUS}=$ cuasativizer, $\mathrm{DIS}=$ distant, DPI $=$ distant past imperfective, DPP $=$ distant past perfective, DTR $=$ detransitivizer, ESV $=$ essive, IMP $=$ imperative, INF $=$ infinitive, INTR $=$ intransitive, IPFV $=$ imperfective, NEG $=$ negative, NPST $=$ non-past, $\mathrm{NZR}=$ nominalizer, $\mathrm{P}=$ patient of transitive verb, $\mathrm{PFV}=$ perfective, $\mathrm{PL}=$ plural, PLAC $=$ pluractional, POS $=$ possessive, $\mathrm{PTCP}=$ participle, $\mathrm{REF}=$ coreferential, $\mathrm{RPP}=$ recent past perfective, $\mathrm{s}=$ single argument, $\mathrm{SAP}=$ speech act participant, $\mathrm{sHR}=$ shifter, $\mathrm{sUP}=$ supine. Unattributed Ye'kwana data in this paper are taken from the author's fieldnotes.

${ }^{4}$ Parentheses in the morpheme line indicate either a morpheme alternating with a zero form or the nature of the epenthetic segment systematically associated with a series of prefixes ([j] for vowel-final prefixes in front of vowel-initial stems and [i] or [i] for consonant-final prefixes on consonant-initial stems). These aim at facilitating comparison between the first and second lines of examples. In the case of consonant-final prefixes, the nature of the epenthetic vowel can only be predicted morphologically (see Cáceres 2011: ch. 4). Note that even though *j- and *i- reconstruct as meaningful prefixes in these contexts (respectively, a relational prefix and a third-person object prefix), no coherent analysis of their meaning can be extracted synchronically given their distribution in Ye'kwana. 


\section{(3a) [ma.kə?.ne] \\ m(i)-akətə-ne \\ 2/3-cut-DPP \\ 'You cut(PAST) it' \\ (3b) [na.kə:.təj] \\ n(i) - aktotə-i \\ 3/3-cut-RPP \\ 'he cut(PAST) it' \\ (3c) [ki.na:.kə?.a.kə] \\ kin(i)-akətə-akə \\ 3/3.DIS-cut-DPI:3}

'he kept cutting it'

The reduction seen in (3a) is obligatory and conforms to the general pattern for non-nasal consonants: $\mathrm{tV} \rightarrow ?$ / $\mathrm{CV} \_\_-\mathrm{CV}$. This reduction exactly follows the patterns reported for the other Cariban languages. The absence of reduction in (3b) is also typical of the patterns reported for other Cariban languages. Rather than conditioning deletion of the final vowel of the stem, the suffix vowel $-i$ forms a diphthong with the final vowel of the stem. Syllable reduction never occurs in the context of this suffix, in Ye'kwana or any of the other languages (see Gildea's [1995] account of this fact in 2.1). In this context, the reduction in (3c) is unexpected: the initial vocalic segment of the suffix does not form a diphthong with the final vowel of the stem (*[ki.na:.kə.təa.kə]), nor does a syllable boundary occur between them (*[ki.na:.kə.tə:.a.kə]), but instead syllable reduction always takes place ([ki.na:.kə2.a.kə]). Nowhere else in the family is syllable reduction attested preceding a vowel-initial suffix.

This leads us to more closely examine these unusual vowel-initial suffixes (see 3 for the full list of suffixes). While they seem to be clearly vowelinitial in examples such as those in (2c), where /kin(i)-emakura-akə/ $\rightarrow$ [ki.ne:.ma.ku.._aa.ke], there are some reducing stems with which they could be analyzed as consonant-initial.

Consider the reducing stems ahict 'move' (4) and Pçict 'drag' (5), which have in common the same three stem final segments, $i c \dot{t}$. These stems are realized reduced or unreduced in the same contexts as $(3 \mathrm{a}-\mathrm{c})$ : they are unreduced in (4b) and (5b) with the suffix $-i$, and reduced in the other contexts where their realization is one syllable shorter, respectively [a.hi?] (4a, 4c) and [?.çii] $(5 \mathrm{a}, 5 \mathrm{c})$. Remarkably, the form of the suffix -akz-previously identified as vowel-initial—is realized as [jakə] (4c) and [cakə] (5c). 


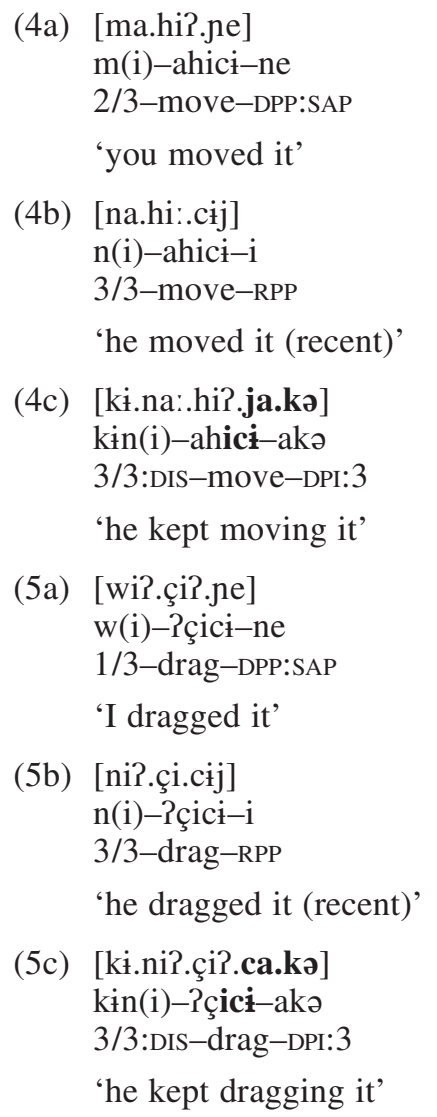

These and other reducing examples (3.2) seem to show that vowel-initial suffixes that condition syllable reduction sometimes behave as if they were consonant-initial. Indeed, the reconstructed forms of Ye'kwana /a/-initial suffixes always begin with a consonantal segment, *j. Clearly then, the unusual behavior of these suffixes is related to idiosyncratic loss of this consonant. When suffixed to a non-reducing stem, the consonant is lost altogether, but when suffixed to a reducing stem, the phonetic realization of that historical consonant can only be partially predicted by the phonetic context. The examples in (4c) and (5c) demonstrate that the consonant can be realized differently even when it occurs in an identical phonetic context: certain stems ending in ict (such as ahict 'move') invariably take [-jakə], while others (such as Pçict 'drag') invariably take [-cakə]. Thus, although there are ways of phonologically predicting when the vowel-initial suffixes are realized as consonant-initial, there seems to be no possible synchronic phonological analysis that would predict the different phonetic realizations of the suffix presented in $(4 c)$ and (5c). I argue that, although most of the characteristics of syllable 
reduction could be easily described with a purely synchronic phonological account, these Ye'kwana facts show that parts of it are better accounted for with a diachronic phonological analysis.

To build this argument, $\mathbf{2}$ introduces regular patterns of syllable reduction in Cariban and illustrates these in Ye' kwana. $\mathbf{3}$ describes the problem of syllable reduction with the synchronically vowel-initial but formerly consonant-initial suffixes and offers a diachronic analysis of each of the different outcomes. 4 discusses a pattern of alternating reducing syllables which prevents the phonetic realization of an unreduced variant of certain stems, contradicting another one of the regularities previously identified in the process of syllable reduction. Finally, 5 draws some overall conclusions.

2. Patterns of syllable reduction in Cariban and in Ye'kwana. Doing a comparative study based on data from five Cariban languages, Gildea (1995) illustrated the then underdescribed phenomenon of syllable reduction. He concluded the particular characteristics of each language illustrated different stages of a diachronic sound change consisting of deletion of a high vowel in a CV syllable and subsequent consonant debuccalization. Since then, the phenomenon has been identified in all languages of the family (Gildea 2012:449) and some additional patterns emerged (word-final syllable reduction in Tiriyó for nouns [Meira 1999:130] and in languages of the Pemóng-Panare macro group [Gildea 2012:449]; creation of an intervocalic voiced-voiceless contrast resulting from syllable reduction in Akawaio, Bakairi, Kuikuro [Gildea 2012:452] and Arara [Ferreira Alves et al. 2016]). Although across all languages of the family regularities can be identified in syllable reduction, the languages present as well a few lexical irregularities, including examples of non-reducing stems where reduction would be expected (e.g., Tiriyo /kumu/ 'palm tree sp.' and /eku/ 'have sexual intercourse'; Sérgio Meira, personal communication), examples of stems with variants having more than one contiguous syllable reduced (e.g., Tiriyó /taike/ 'negative particle' with reduced variants [tah], [ta:] and [ta]; Sérgio Meira, personal communication), and examples of reducing stems with non-high vowel nuclei (e.g., the ten examples scattered throughout Gildea's 1995 paper).

Ye'kwana is not different in that it partly conforms to most of the generalizations made about syllable reduction and has some marginal irregularities or special cases due to interactions with other morphophonological processes. However, two of the "deviant" patterns found in Ye'kwana apply to sufficiently sized portions of the lexicon from which a different set of regularities can be identified. As such, the "deviant" cases are not really two more irregularities to add to the previous list but regular patterns, if taken in the context of historical phononological processes that are Ye'kwana-specific.

After making a list of the general patterns in the comparative Cariban basic syllable reduction in $\mathbf{2 . 1}$, the following sections address the ways in which some 
of the listed characteristics of the general pattern interact with distinctive phonological and prosodic features of Ye'kwana: $\mathbf{2 . 2}$ presents those phonological and morphophonological structures of Ye'kwana that put additional constraints on regular patterns of syllable reduction, and then $\mathbf{2 . 3}$ clarifies the independence of the prototypical Cariban iambic stress system vis-à-vis syllable reduction.

2.1. Cross-Cariban patterns generalized. Comparative observation reveals certain regular patterns in the process of syllable reduction: in all Cariban languages, reduction can synchronically be (i) observed at morpheme boundaries, (ii) when the final syllable of a verb stem is a double-sided open syllable with a high vowel $\{\mathrm{i}, \mathrm{i}, \mathrm{u}\}$, (sometimes mid $\{\mathrm{e}, \partial, \mathrm{o}\}$ ) and, to the right, (iii) a suffix starting with a CV sequence allows the final syllable to remain open, conditioning a combination of (iv) vowel deletion and (v) simplification of the resulting consonant cluster. The label "syllable reduction" designates the alternation of a short form of a stem with a long form. In languages such as Tiriyó, where more than one short form per reducing stem can be identified, the stem is said to be realized at different grades (the zero grade, the coda or C grade, and the full or CV grade [Meira 1999:127]). In the rest of this subsection I comment on the first three regular patterns and give examples for each.

2.1.1. On localization of syllable reduction. Gildea $(1995,2012)$ concentrates mostly on the phenomenon at the right morpheme boundary of verbs but has also found it to occur word finally for nouns in the Pemóng-Panare macro group (Gildea 2003). However, across the family, syllable reduction has also been found to occur at the left edge of noun roots and curiously not at the left edge of verb roots (Spike Gildea, personal communication, and 2.2.3 for Ye'kwana). No mention is made in the comparative literature about reduction of postpositions, which is the only other word class that can take a variety of prefixes (on the right, postpositions and adverbs are only attested to have one suffix available and this suffix does not condition syllable reduction).

From a historical point of view-supported in many cases by comparative evidence-it could be assumed that a stem-internal consonant cluster in which the first segment is glottal or nasal is the result of a process similar to syllable reduction. Gildea (1995:98) reconstructs such an example:

From Proto-Carib *esika 'bite'

$\begin{array}{lll}\text { (6a) } * \text { esika }>\text { es.ka } & \text { (Yukpa, Sikuyana) } \\ \text { (6b) *esika }>\text { eh.ka } & \text { (Panare) } \\ \text { (6c) } * \text { esika }>\text { ee.ka } & \text { (Carib, Macushi, Tiriyó; Ye'kwana) }\end{array}$

Other similar examples abound in Ye'kwana lexical roots:

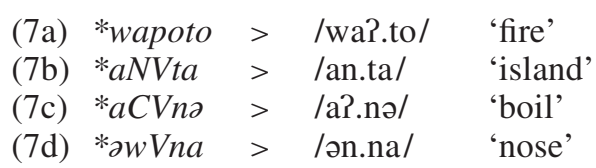


However, in the absence of alternation between a reduced grade of said stems (in other words, of a form of the stem with an internal consonant cluster) and a full grade (a form with a double-sided open syllable in place of the consonant cluster), generalizations about syllable reduction at morpheme boundaries will not necessarily overlap with generalizations that can be made about inherited non-alternating consonant clusters-stem internally but also at morpheme boundaries (see $\mathbf{4 . 1}$ for cases of the latter in Ye'kwana).

Separating similar sound mechanisms according to their locus of occurrence with respect to morpheme boundaries is important in that the evidence found in one locus is not necessarily evidence of the characteristics of the other locus. For instance, it is shown further in this section that syllable reduction at morpheme boundaries in Ye'kwana does not affect syllables containing front high vowels (2.2.4) and that reduction never results in simple compensatory lengthening (2.2.5); however, (6c) shows that a protosyllable containing a high vowel is found in Ye'kwana as compensatory length (*esika $\rightarrow e e . k a$ ). This presumably means that at some point in the history of the language there was a process of syllable reduction with different rules than those found synchronically.

2.1.2. On the characteristics of the reducing syllable. It is always the case that the reducing syllable is part of an underlying or internally reconstructed double-sided open syllable. Were the reducing syllable or its preceding syllable closed, syllable reduction would create clusters of three or more consonants, and this kind of cluster is very rarely attested in the languages of the family (see, e.g., syllable structure in Ye'kwana in 2.2.1). In contrast to the rigidity of the structure of the syllable, the nature of the vowel is variable: reducing syllables most regularly contain a high vowel, but it is not uncommon to have reducing syllables with mid-vowels. Examples below show stems for which the last syllable containing one of the three Cariban high $(8 \mathrm{a}-\mathrm{c})$ or mid $(8 \mathrm{~d}-\mathrm{f})$ vowels reduce.

(8a) aki ah 'to misfire, make a mistake' (Panare, Gildea 1995:66)

(8b) enepi $\sim$ enex 'to bring', (Carib, Hoff 1968:126)

(8c) utu $\sim$ h 'to give' (Panare, Gildea 1995:65)

(8d) on $\sim$ on $\quad$ 'to see' (Hixkaryana, Derbyshire 1985:90; p.115)

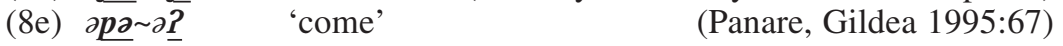

(8f) kamo $\underline{\sim a n}^{-}$'empty, pour' (Macushi, Williams 1932:241)

As for reduction of syllables containing the low vowel, comparatively, there is evidence that some stem-internal ${ }^{*} \mathrm{CVCa} \ldots$. became CVC . . , but at morpheme boundaries, there are only three reported cases of reduction of a Ca syllable: the -ja 'IPFV' suffix reduces in Tiriyó (Meira 1999:300) and kurima kurin and eka ek have been cited for Macushi (Gildea 1995:72, 87). ${ }^{5}$

\footnotetext{
5 The examples in Macushi might in fact be examples of iambic vowel deletion rather than of non-rhythmic syllable reduction.
} 
TABLE 1

Conditioning and Non-Conditioning Contexts for Syllable Reduction

\begin{tabular}{|c|c|c|c|c|}
\hline & \multicolumn{3}{|c|}{ No Syllable Reduction } & Syllable Reduction \\
\hline & $\$ C C V$ & $\$ V$ & $\begin{array}{l}\text { reflex of } \\
\quad *-r i\end{array}$ & $\$ C V$ \\
\hline Panare & -hрә, -htерi, -эрәh & $-i$ & $-\eta$ & $\begin{array}{l}\text {-taane, -toipe, -yake, -sehpe, -nәpah, } \\
\text {-nepe }\end{array}$ \\
\hline Carib & $-x p a$ & $-i$ & $-r i$ & - poti, $-k o,-s a \eta,-n e \eta$ \\
\hline Macushi & -hpi, -hsan & $-i$ & $-r i$ & $-p a i,-p \dot{t} t \dot{t},-t \dot{t},-s a h$ \\
\hline Apalai & -Ppiri & -ase, -ano & $-r i$ & $-k o,-n o$ \\
\hline
\end{tabular}

2.1.3. On the characteristics of the suffix following the reduced syllable. Gildea (1995) found that -CV suffixes conditioned syllable reduction, ${ }^{6}$ whereas -CCV or vowel-initial suffixes did not. In his analysis, these two different outcomes can be predicted from syllable structure. The two types of suffixes with which syllable reduction is regularly observed not to occur make the preceding syllable heavy: a CC sequence preceding a vowel is always heterosyllabic - there are virtually no onset consonant clusters in Cariban (only in a few languages some ${ }^{*} \mathrm{CVrV}>\mathrm{CrV}$ ), so $\mathrm{CCV}$ suffixes make the preceding syllable heavy by adding a coda; a VV sequence forms a diphthong in all previously described Cariban languages and as a consequence vowel-initial suffixes make the preceding syllable heavy by making its nucleus a branching nucleus. Table 1 presents a list of the different suffixes that Gildea (1995) found to either condition or not condition syllable reduction.

Gildea had also observed that an unreduced form of roots/stems could always be found as one of the variants of these morphemes (but see section on alternating reducing syllables in Ye'kwana [4.2] for the pattern that contradicts this generalization).

2.2. Syllable structure and syllable reduction in Ye'kwana. This section starts by presenting characteristics of Ye'kwana phonology (2.2.1) that are relevant for understanding the phonological and morphological structures presented in $\mathbf{2 . 2 . 2}$ and $\mathbf{2 . 2 . 3}$ that actually condition syllable reduction in the language. Possible factors that prevent reduction with other segments are also discussed in those sections. The last two sections describe the phonetic characteristics that are unique to Ye'kwana pertaining specifically to the vowels of reducing syllables (2.2.4) and the changes to the consonant of the reducing syllable (2.2.5).

\footnotetext{
${ }^{6}$ Excluding reflexes of the action nominalization suffix $* r i$ : there are no attested cases of reduction in front of this suffix in any of the modern languages.
} 
TABLE 2

Ye'kwana Consonant Phonemes

\begin{tabular}{lllllll}
\hline \hline & Labial & Alveolar & Post-alveolar & Palatal & Velar & Glottal \\
\hline Plosive & & $\mathrm{t}$ & & $\mathrm{c}$ & $\mathrm{k}, \mathrm{k}^{\mathrm{w}}$ & ? \\
Nasal & $\mathrm{m}$ & $\mathrm{n}$ & & $\mathrm{n}$ & & \\
Fricative & & $\mathrm{s}$ & $\mathrm{S}$ & $\mathrm{c}$ & & $\mathrm{h}$ \\
Tap & & & $\underline{\varsigma}$ & & & \\
Approximant & & & & $\mathrm{j}$ & $\mathrm{w}$ & \\
\hline
\end{tabular}

TABLE 3

Ye' kwana Vowel Phonemes

\begin{tabular}{llll}
\hline \hline & Front & Central & Back \\
\hline High & i, i: & i, i: & u, u: \\
Mid & e, e: & ə, ə: & o, o: \\
Low & & a, a: & \\
\hline
\end{tabular}

2.2.1. The basics of Ye'kwana phonology. Ye'kwana presents compact inventories of phonemic consonants and vowels in terms of number of contrasts. Synchronically, 15 and 14 segments can be identified respectively in each inventory (tables 2 and 3 ).

At an earlier stage of the language, these inventories were no doubt even smaller, without length distinctions for vowels, with fewer post-alveolar and palatal consonants, and with no labialized velar and glottal stops. Synchronically, there are certain morphophonological processes that suggest mechanisms for these additions: syllable reduction involves alternations with the glottal stop, palatalization involves alternation of most non-palatal consonants with palatal consonants and the post-alveolar fricative, and iambic lengthening creates phonetic long vowels. These processes interact with one another in specific ways so that it would be difficult to explain syllable reduction without presenting palatalization and metrical stress. For obvious reasons, it is also necessary to understand the phonotactic restrictions of the Ye'kwana syllable before presenting syllable reduction — but here again, specific restrictions have their origin in syllable reduction, palatalization or iambic lengthening. Syllable structure and the latter two phenomena are further described for Ye'kwana in this section.

2.2.1.1. Syllable structure. In Ye'kwana, syllables are maximally of the types $(\mathbf{C}) \mathbf{V}(:) \sim(\mathbf{C}) \mathbf{V}(\mathbf{C})$, where vowel length and coda consonants are mutually exclusive. Onsets and codas are not necessary to form a syllable, and neither one is ever complex. There are also no vocalic diphthongs: all 
vowel sequences of different vowels are heterosyllabic (but these only exist at morpheme boundaries). However, all logical sequences of a vowel plus a following approximant are found in the language. Only four consonants are phonemically found in coda position /n, j, w, ?/ and of these, only /j, w/ word-finally. Note that word-medially $/ \mathrm{n}, \mathrm{j}, \mathrm{w} /$ allow a variety of phonetic realizations: the phoneme $/ \mathrm{n} /$ is realized as $[\mathrm{n}],[\mathrm{m}]$, [n], [n] or [m] depending on the context and $/ \mathrm{j}, \mathrm{w} /$ are in most cases realized as gemination of the following phonetic consonant after palatalization and rounding (/jawha/ is

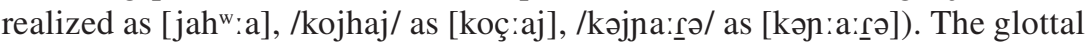
stop $/ \mathrm{R} /$ seems to be a more recent addition to the consonantal inventory since it can only be realized contrastively in coda position. ${ }^{7}$ Here it is relevant to point out that syllable reduction is phonotactically structure preserving - that is, no consonant clusters arise that are not elsewhere attested in morphemes. This differs from iambic vowel reduction described for Macushi (Kager 1997:472).

2.2.1.2. Palatalization. This process affects all non-palatal consonants except for the labialized velar and glottal stops. It occurs in the context of a preceding front high segment [i] or [j]. There are only two consonants that have a one-to-one correspondence with a palatalized variant $(9 \mathrm{a}, \mathrm{b})$. The two non-palatal stops are both realized as the palatal stop (9c) and the two nonpalatal nasals as the palatal nasal (9d). Both the labio-velar approximant and the flap are realized as the palatal approximant in this context $(9 \mathrm{e}, \mathrm{f})$ with a second possible palatal variant for the flap only (9f).

$\begin{array}{llll}(9 \mathrm{a}) / \mathrm{s} / & \rightarrow & {[\mathrm{j}]} & / \mathrm{i}_{-} \text {or } / \mathrm{j}_{-} \\ (9 \mathrm{~b}) / \mathrm{h} / & \rightarrow & {[\mathrm{c}]} & / \mathrm{i}_{-} \text {or } / \mathrm{j}_{-} \\ (9 \mathrm{c}) / \mathrm{t}, \mathrm{k} / & \rightarrow & {[\mathrm{c}]} & / \mathrm{i}_{-} \text {or } / \mathrm{j}_{-} \\ (9 \mathrm{~d}) / \mathrm{m}, \mathrm{n} / & \rightarrow & {[\mathrm{n}]} & / \mathrm{i}_{-} \text {or } / j_{-} \\ (9 \mathrm{e}) / \mathrm{w} / & \rightarrow & {[\mathrm{j}]} & / \mathrm{i}_{-} \text {or } / \mathrm{j}_{-} \\ (9 \mathrm{f}) / \underline{\mathrm{s}} / & \rightarrow & {[\mathrm{j}, \mathrm{c}]} & / \mathrm{i}_{-} \text {or } / \mathrm{j}_{-}\end{array}$

This process is pervasive throughout the language and has probably shaped the lexicon in such a way that it could be in Ye'kwana the source of observed absences of syllable reduction in contexts where it would be expected to take place (cf. 2.2.2 and 2.2.4).

2.2.1.3. Iambic lengthening. Prosodic lengthening of a short vowel occurs following an iambic pattern for light syllables with footing starting on the left edge of the word (Cáceres 2007:102-15):

(10) CV.CV.CV.CV ... $\rightarrow$ (CV.CV:.)(CV.CV:.) ...

\footnotetext{
${ }^{7}$ The syllabic position of the glottal stop is clear when followed by another consonant and it could arguably be considered ambisyllabic intervocalically. However, a discussion of the latter case is outside the scope of this paper. Naturally, at the phonetic level, it can also be found as the onset of phonemic vowel-initial word-forms.
} 
In this system the last syllable is extrametrical and no degenerate feet are formed. Systems with the same characteristics have been described for Hixkaryana (Hayes 1995:205-8), Tiriyó (Meira 1998), and Kari'ña (Álvarez 2003). Notice that, unlike what has been described for Macushi (Abbott 1991:147, Kager 1997, McCarthy 2009), in neither of these systems is there a phenomenon of rhythmic vowel-deletion of the light syllable of iambs.

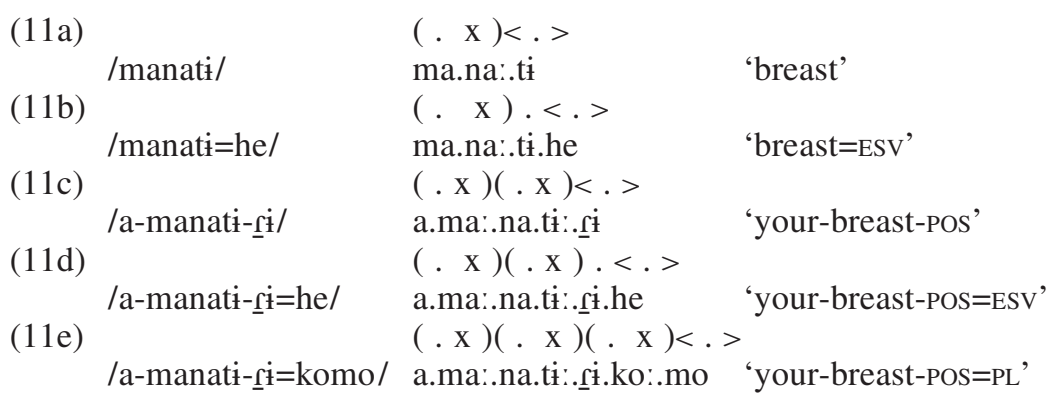

Whenever there are heavy syllables-closed or with a phonemic long vowel-the heavy syllable is always the head of a foot; thus, for the same number of syllables, different metric patterns are possible depending on the structure of the syllables. The following are examples of four-syllable words where iambic lengthening only occurs if the head of an iamb is a light syllable: in the third syllable of (12a) and the second of (12c).

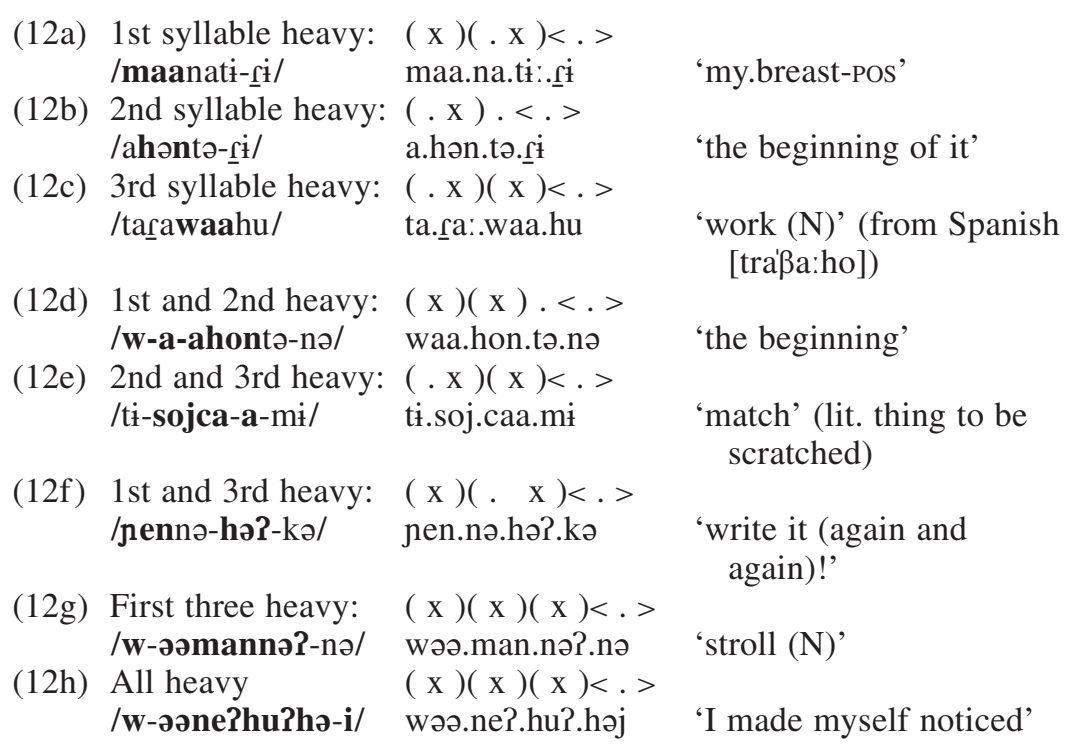

In Ye'kwana, rythmic vowel lengthening does not seem to be correlated to any particular pitch pattern. In the few languages of the family where there 
are claims about primary stress, iambic lengthening is treated as secondary stress. However, in Ye'kwana, there has not yet been a definite claim about another kind of stress that would relegate iambic lengthening to a secondary stress phenomenon. It might well be that the metric system is the closest the language gets to a stress system. In terms of interactions with syllable reduction, iambic lengthening seems to operate after reduction as shown in $\mathbf{2 . 3}$.

Most of the morphophonemic alternations present in Ye'kwana are parallel to different degrees to those found in the other languages of the family (see Gildea [2012:452] for references on the description of iambic metric systems; Meira and Franchetto [2005] for the most widespread palatalization patterns found throughout the family; Álvarez [2016:21-22] for palatalization patterns in Kari'ña that resemble more closely those found in Ye'kwana; and Meira et al. [2010] for ablaut patterns). What is noteworthy about Ye'kwana is the extent of palatalization and the particularities of syllable reduction that are the focus of this paper.

2.2.2. Phonological conditions for syllable reduction. In Ye'kwana, syllable reduction always occurs before the following segments: $/ \mathrm{t}, \mathrm{k}, \mathrm{h}, \mathrm{n} /$ and /a, e/ (see examples in 3.2). There is no obvious way of grouping all of these.

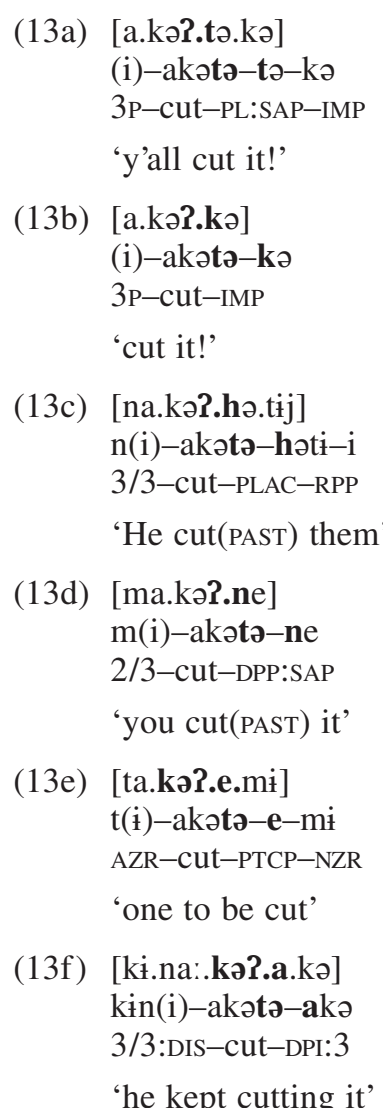


Preceding $/ \underline{s} /$ and $/ \mathrm{w} /$, there are two examples at the left boundary of noun roots where reduction is observed:

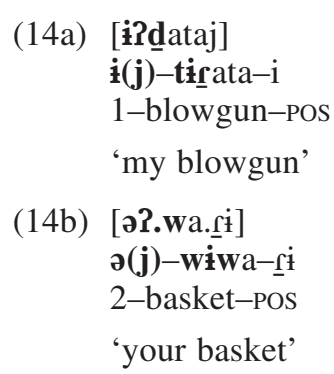

Reduction does not occur preceding the front high vowel /i/ and the glottal stop /R/.

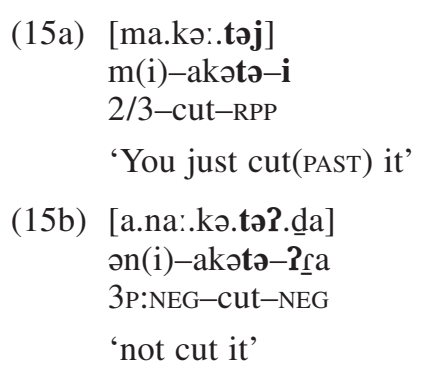

There is no evidence of syllable reduction at morpheme boundaries immediately preceding the following segments: /c, s, $\int, \mathrm{c}, \mathrm{m}, \mathrm{n}, \mathrm{j} /$ and /i, u, ə, o/.

This inventory includes the five consonants for which a homophonous phonetic palatalized variant of a "basic" (i.e., non-palatalized) consonant exists. This fact is not surprising since the source of palatal consonants is presumably palatalization that no longer alternates following the segments $/ \mathrm{i}, \mathrm{j} / \mathrm{:}$ the high front vowel is never found as the nucleus of a reducing syllable (see 2.2.4), and no syllable with an approximant in coda position would meet the syllabic structure needed for reduction. However, the fifth consonant of that type $/ \mathrm{j} /$ already existed in the inventory before the advent of palatalization (i.e., it has been reconstructed to Proto-Carib [Gildea 2012:448]), which correlates with it being preceded by reducible vowels and not just /i/.

The absence of evidence for the other two consonants of this list is more accurately described as insufficient evidence. Unfortunately, there are no suffixes with initial $/ \mathrm{s}, \mathrm{m} /$, and a search for roots or stems capable of taking a prefix (that is, among the 617 verbs, 116 postpositions, and a subset of the 765 total nouns in the available corpus) yields confounding facts.

In order to test whether syllable reduction occurs at the morphological boundary with prefixes (on the left boundary of roots) it is necessary to find words in which the first syllable has the potential to be reduced (2.2.4) and the second syllable has the sought consonant in onset position (for this section, 
$/ \mathrm{CVsV} /$ and $/ \mathrm{CVmV} /$ ). However, morpholexical constraints on nouns result in only 75 morphologically possessable nouns in the available lexicon that are CVCV-initial and contain one of the vowels attested in reducing syllables in Ye'kwana (/i/, /u/ and /ə/). Of these, only five nouns are attested undergoing reduction of the first syllable - those in (14a, b), (18), (19), and tuna 'water'; 47 nouns are attested as not undergoing reduction; and 12 nouns have unknown possessed forms. As for verbs, it was mentioned earlier that throughout the Cariban family verbs never present syllable reduction alternations at the left morphological boundary, but the same turns out to be true for postpositions, at least in Ye'kwana.

With these lexical constraints in mind, we can now turn to the few examples having the phonotactic potential for evidence of reduction with $/ \mathrm{s} /$ and $/ \mathrm{m} /$ at morpheme boundaries.

For /s/, only three nouns with these phonotactic characteristics were found (no verbs or postpositions). Of the three, two are morphologically unpossessable nouns and the third is a Spanish borrowing /kusarija/ 'teaspoon' which is not affected by syllable reduction when possessed (/o-kusarija-i/ > [əku:sasi:jaj]).

For $/ \mathrm{m} /$, the available corpus yields one verb (timi 'fish with barbasco'), one postposition (humə 'together'), and two morphologically possessable nouns (himi 'neck' and kimi 'knife') with the required phonotactic features for testing reductability in this context. Unsurprisingly, the verb and the postposition do not reduce, but neither do the two nouns.

Turning to vowels, at the right boundary, there are no suffixes starting with /i/, /i/, /u/, /ə/ or /o/. ${ }^{8}$ At the left boundary, potential examples would have to be sought where a $(\mathrm{C}) \mathrm{V}$-final prefix meets a vowel-initial root since sequences of different vowels are only found at boundaries (i.e., no CV.V-initial root can be expected to be found; see 2.2.1). However, with vowel-initial stems containing any vowel, all available prefixes are of the form C-, VC- or CVC-and the initial vowel of these stems automatically forms a syllable with the final consonant of the prefix, making it so vowels at the left boundary never form onsetless syllables that could condition reduction of the preceding syllable. But even if the vowel were to not syllabify with any of the existing prefix shapes, with VC- and CVC- prefixes the initial syllable would be closed and thus would not allow reduction.

2.2.3. Morphological localization of syllable reduction. The phenomenon of syllable reduction that is the subject of this paper occurs at morpheme boundaries. Logical possibilities predict that syllable reduction could be observed at the left boundary of roots between prefixes and roots but also

\footnotetext{
8 Absence of evidence in front of /i/ and / $/$ / could also be explained phonotactically, since, in suffix position, occurring after a vowel, there would be no way of distinguishing these from the approximants /j/ and /w/.
} 
among prefixes and similarly at boundaries to the right of the root. However, as has been shown in the preceding section, there are often phonotactic constraints or lexical limitations (even beyond the available corpus) that reduce these possibilities. This section lists and illustrates the actual localizations of syllable reduction in Ye'kwana.

It is interesting to note that across the Cariban family there is no syllable reduction at the left edge of verb stems. This contrasts, on the one hand, with the behavior observed at the right edge of verb stems and on the other hand with the behavior observed at the left edge of noun stems (Gildea, personal communication). Cáceres (2011:80-84) has noted some of the same contexts for syllable reduction in Ye'kwana. For examples of syllable reduction at the right morpheme boundary of verbs see (3-5), (13), (20-25), and (35-42).

At the left edge of verb roots, the only root with a potentially reducing syllable does not reduce (timi mentioned above). However, there are a series of verb roots with an initial $\mathrm{PC}$ or $\mathrm{NC}$ cluster which could be interpreted as having a reduced first syllable.

(16a) [tip.do.tə]

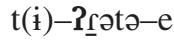

AZR-cross-PTCP

'crossed'

(16b) [ki.ni?.jə.təj]

kin(i)-?jatว-i

3/3:DIS-cross-RPP

'he crossed it'

(16c) [ti.we?.də.tə]

$\mathrm{t}(\mathrm{i})-\mathrm{w}-\mathrm{e}-\mathbf{2}$ @ətว-e

AZR-INTR-DTR-cross-PTCP

'having crossed'

(17a) [tin.ne.hen.ta]

$\mathrm{t}(\mathrm{i})-$ nnehenta-a

AZR-spoil-NPST

'be spoiled'

(17b) [in.ne.hen.ta.ㅁ]

(i)-nnehenta- $\underline{-}$ i

3P-spoil-IPFV

'He is being spoiled'

(17c) [an.ne.hen.ta.[i]

a(j)-nnehenta- $\underline{i} \dot{i}$

2P-spoil-IPFV

'you are being spoiled' 
These never alternate with a full syllable and thus are not considered synchronic syllable reduction. Therefore, for verbs, the absence of reduction is of two kinds: absence of context allowing syllable reduction and absence of alternation between a reduced and an unreduced allomorph.

Syllable reduction on verbs is symmetrically opposite to syllable reduction on nouns, where it is only found to occur at the left edge as in the following examples:

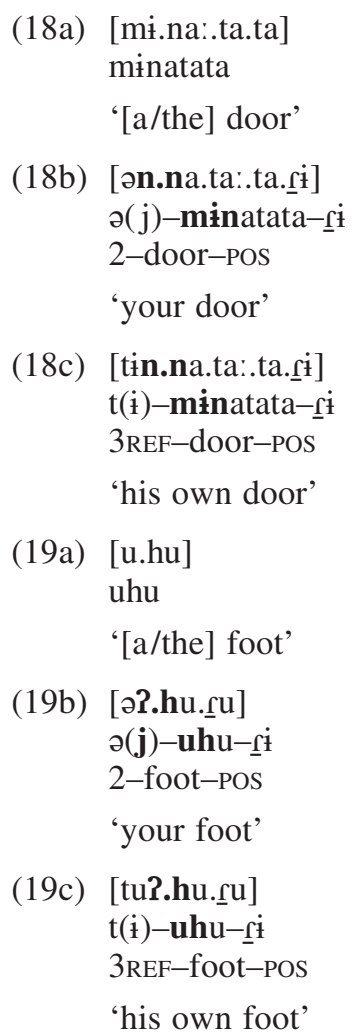

As for reduction at the right edge of noun stems, Cáceres (2011:81-82) argues the phonological shape of the synchronically productive nominal suffixes available limits the contexts in which syllable reduction could occur on this side. Indeed, the only three suffixes that can be directly affixed on nouns stems are $-\underline{i} \dot{t},-i$ and $-\boldsymbol{P} h \underline{i} \underline{\mathbf{t}} \dot{t}$. Comparative observations about modern reflexes of the Proto-Carib suffix *-ri 'action nominalizer' seem to show that they are exceptional in all Cariban languages as they never condition syllable reduction. Ye'kwana provides an additional example of this behavior, not only on verbs, but also on nouns (where the $-\tilde{t} \dot{t}$ suffix is a morpheme indicating possessed status). In the case of -C or -CCV suffixes such as $-i$ and $-? h \hat{i}_{-} \dot{t}$, the general pattern (see 2.1) predicts they prevent syllable reduction. 
Although contextual justification accounts for the absence of reduction alternation at the right edge of noun stems, no phonological context can be invoked for the absence of this alternation at the left edge of verb stems. Perhaps the origin of this absence can be related to rarity of occurrence: in Ye'kwana there is only one known form of the verb that can occur with no prefixes - the potential agent adverbial with the suffix -:tz-which is morphosyntactically limited to transitive verbs and pragmatically limited to those verbs taking a rather agentive A argument. Also noteworthy is the existence of $t$-roots, which I (Cáceres 2011:127-28) suggest might have originally been reducing roots that followed a specific pattern for third person object marking.

Finally, reduction at boundaries between affixes seems to be historically conditioned as different affix collocations yield different results in Ye'kwana: some affixes show signs of having undergone reduction but never show an unreduced syllable (e.g., -Pra 'negative' in Ye'kwana, compared to hira hra in Hixkaryana [Derbyshire 1979:48]), and a clitic that does not condition syllable reduction on nouns conditions reduction of certain suffixes (Cáceres 2011:84 on affix reduction with $=$ komo).

2.2.4. Vowels affected by syllable reduction. Although the generalization in Gildea (2012:449) presents the phenomenon as affecting syllables containing high vowels, it is more accurate to specify that it is much more frequent for a high vowel to reduce (see, e.g., Meira [1999:130]) but that other vowels may also be the target of syllable reduction. Vowels deleted in each of the five languages presented by Gildea (1995) include the three high vowels /i, i, u/ with some cases of /e/ deletion in Hixkaryana, in addition to some cases of /o/ and /a/ deletion in Panare and two examples of deleting /a/ in Macushi (kurima 'splash' and eka 'bite').

Thus, the general pattern of syllable reduction almost makes it seem as if all vowels could delete. However, a closer look at other phonological or morphophonological processes of each language suggests this might be due in part to language-specific phenomena. For instance, examples of Hixkaryana where a mid-front vowel appears to reduce might actually be examples of reduction of /i/ in its realization [e] as this language does not preserve a phonological height distinction for front vowels.

In Ye'kwana, the vowel set that is affected by synchronic syllable reduction is limited to $/ \mathrm{i} /, / \mathrm{u} /$, and $/ \mathrm{\partial} /$, and $[\mathrm{u}]$ and $[\mathrm{o}]$ in contexts where these are presumably rounded realizations of the corresponding central vowels. ${ }^{9}$ However, although in the comparative pattern the generalization includes syllables with

\footnotetext{
${ }^{9}$ The central vowels $/ \mathbf{i} /$ and /ə/ are realized rounded when an adjacent syllable contains /u, $\mathrm{o} /$, or $[\mathrm{u}, \mathrm{o}]$, for example, /n-ə-emomi-i/ $\rightarrow$ [noomomij] 'he entered' for regressive rounding

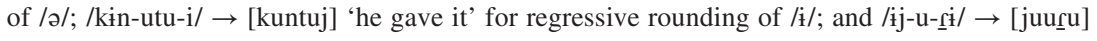
'my bread meal' for progressive rounding of /i/. There is however, no evidence of progressive rounding of $/ \curvearrowright /$.
} 
a high vowel as the preferred target for syllable reduction, there are no attested cases of a reducing syllable at morpheme boundaries containing /i/.

Furthermore, even within the more limited set of contexts for syllable reduction, the process is not absolutely regular. Given the above description, it would be expected that any open syllable containing /i/, /u/, or /ə/, and any consonant as the onset except the flap, would undergo syllable reduction when the following segment conditions it. However, although for more than $80 \%$ of the verb roots with final /CVCi/ and /CVCu/ syllables (95 verb roots with these characteristics), syllable reduction takes place; in the case of roots with /CVCə/ syllables, fewer than half of a total of 48 roots reduce. Further counts reveal that there might be a lexical bias that motivates the absence of reduction for syllables with /i/ as the nucleus: there are only seven verb roots that are /i/-final, of which only the two /CVCi/ do not reduce. The pervasive process of palatalization might also have been historically in competition with syllable reduction.

2.2.5. Changes to the consonant of the reducing syllable. The type of simplification observed throughout the family is varied and depends on the nature of the original consonant (obstruent, nasal, or liquid) and the different conditioning contexts. Gildea (1995) argues the resulting shape of the neutralized consonant depends also on the degree of historical change undergone by each language. As such, he argues that the process of syllable reduction is better understood from a comparative perspective. Indeed, the two special cases developed in $\mathbf{3}$ and $\mathbf{4}$ present two different illustrations that support the necessity of this kind of analysis.

In the case of obstruents, Gildea had observed two possible robust outcomes: a stage of simple vowel deletion ( $\mathrm{CV} \rightarrow \mathrm{C}$ in Hixkaryana) and three different types of debuccalization of the consonant $(\mathrm{CV} \rightarrow \chi$ in Carib, $\mathrm{CV} \rightarrow \mathrm{h}$ in Apalaí, and CV $\rightarrow ?$ in Panare and Macushi). Additionally, a particular context in Carib showed complete reduction of the syllable with compensatory lengthening (Hoff 1968:66). Phonologically, Ye'kwana obstruents behave in syllable reduction as do those in Panare and Macushi, with no special cases of compensatory lengthening. Table 4 compares the outcome of syllable reduction for the velar glottal in the five languages presented in Gildea in addition to Ye'kwana. Compare the final syllable of the stem in bold in the second column with the final segment of the verb stem in the fourth column.

All of the obstruents in Ye'kwana follow the same pattern illustrated in (13) except in front of nasals and vowels, where some present special cases. Special cases with the vowel initial suffixes are illustrated in 3.2. Special cases of assimilation of the coda of the reducing syllable to a nasal occur for $\mathrm{CiCV}$ with palatalization $(20 \mathrm{a}-\mathrm{c})$ and $\mathrm{CVwV}$ with simple assimilation $(21 \mathrm{a}, \mathrm{b})$.

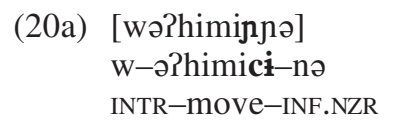

'[a/the] moving' 
TABLE 4

Syllable Reduction for kV Syllables in Six Languages

\begin{tabular}{|c|c|c|c|c|c|}
\hline \multirow{2}{*}{$\begin{array}{l}\text { Language } \\
\text { Hixkaryana }\end{array}$} & \multicolumn{2}{|c|}{ Unreduced Stem } & \multicolumn{2}{|c|}{ Reduced Stem } & \multirow{2}{*}{$\begin{array}{c}\text { Source } \\
\text { Derbyshire } \\
1985: 81,79\end{array}$} \\
\hline & t-omoki $\mathbf{k}$-txhe & $\begin{array}{l}\text { 'when he } \\
\text { comes' }\end{array}$ & n-omok-je & 'he came' & \\
\hline Carib & w-onik $\underline{k i}$ & 'sleeping' & onix-poro & $\begin{array}{l}\text { 'counterexpected } \\
\text { sleep' }\end{array}$ & Hoff 1968:157 \\
\hline Apalai & $j \dot{i}$-nikit-ase & 'I slept' & nih-se & 'having slept' & $\begin{array}{l}\text { Koehn and } \\
\text { Koehn } \\
\text { 1986:123 }\end{array}$ \\
\hline Panare & j-a?muku-n & $\begin{array}{l}\text { 'he's going } \\
\text { to gather } \\
\text { it' }\end{array}$ & n-a?mu?-jah & 'he gathered it' & $\begin{array}{l}\text { Payne and } \\
\text { Payne } \\
\text { 2013:53 }\end{array}$ \\
\hline Macushi & ekaremeki-j-ja & $\begin{array}{l}\text { 'he will } \\
\text { tell' }\end{array}$ & ekareme?-to?pe & 'in order to tell' & $\begin{array}{l}\text { Abbott } \\
\quad 1991: 65,35\end{array}$ \\
\hline Ye'kwana & kin-womokí-j & $\begin{array}{l}\text { 'he waited } \\
\text { for him' }\end{array}$ & o-womo?-ne & $\begin{array}{l}\text { 'he waited for } \\
\text { you' }\end{array}$ & (primary data) \\
\hline
\end{tabular}

(20b) [wəวminnə]

w-əomicə-nə

INTR-gather.manioc-INF.NZR

'[a/the] manioc-gathering'

(20c) [wetadinnə]

w-etarimi-nə

INTR-whistle-INF.NZR

'[a/the] whistling'

(21a) [waidennen

w-a?

INTR-speak-INF.NZR

'[a/the] speech'

(21b) [wekanne]

w-ekawi-ne

1/3-extend.on.grill-DPP:SAP

'I made grilled [tobacco/manioc]'

In the case of reducing syllables with nasal onsets, three possible outcomes have been found across the family: vowel deletion without assimilation to place (in Hixkaryana), assimilation to a homorganic nasal (systematic in Macushi, with exceptions in Panare and Carib), or nasalized compensatory lengthening (in Apalai). Ye'kwana is of the second type.

(22a) [a.je:ka.tin.tə.kə]

ə(j)-ekatimi-tə-kə

2-run-PL:SAP-IMP

'y'all run!' 
(22b) [a.je:.ka.tin.kə]

ə(j)-ekatimi -kə

2-run-IMP

'run!'

(22c) [ne.ka:.tim.mo.tij]

n(i)-ekatimi-həti-i

3-run-PLAC-RPP

'he ran all over'

(22d) [ne.ka:.tin.ne]

n(i)-ekatimi-ne

3-run-DPP:SAP

'he ran'

(22e) [ti.we:.ka.tin.ye.mi]

$\mathrm{t}(\mathrm{i})-\mathrm{w}-$-ekatimi $-\mathbf{e}-\mathrm{mi}$

AZR-INTR-cut-PTCP-NZR

'one who is to run'

(22f) [ki.ne:.ka.tin.ya.kə]

kin(i)-ekatimi-akə

3/3:DIS-cut-DPI:3

'he kept running'

In the case of liquids, only two kinds of outcomes had been observed: simple vowel deletion (in Hixkaryana) and complete loss of the syllable (in Panare) with compensatory lengthening of the preceding vowel (in Macushi and Carib). Gildea (1995:95) found no evidence for reduction of liquids in Apalai, being unable to confirm more than an absence of evidence. A search in Meira's Apalai Toolbox database (Meira n.d.a) confirms that none of the 17 verb roots in ri\$/ri \$/ru\$ reduce. Ye'kwana presents a similar pattern to

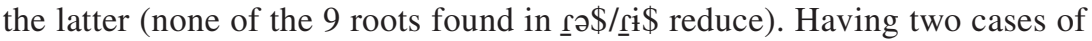
absence of syllable reduction with liquids confirms the pattern and has to be added to the behavior of this type of syllable. The fact that throughout the family the only known verbal suffix with a liquid onset (reflexes of proto *-ri) prevents syllable reduction also highlights a special treatment reserved for flaps.

2.3. Syllable reduction and stress: Two independent phenomena. Gildea (1995:65-66) relates to stress the contexts in which syllable reduction does not take place by saying that $-\mathrm{CCV},-\mathrm{VCV},-\mathrm{C}$, and $-\mathrm{V}$ suffixes add a coda to a preceding CV syllable, making it heavy and thus attracting secondary stress. However, Gildea (1995:73-74) further explains that there is no synchronic unified motivation in terms of stress in the cases where final syllables of verb stems do reduce and also found that in some cases syllable 
reduction might be motivated by vowel syncope in the syllable preceding primary stress in the verb word. In his later comparative work, Gildea (2012) does not relate syllable reduction directly to stress (only indirectly, by mentioning in passing that both processes interact with vowel length).

Further support for the lack of motivation from stress placement in syllable reduction can be found in Ye'kwana. In this language, the same metric contexts can exhibit different results with respect to syllable reduction whereas reduction consistently takes place in certain morphological constructions even if the metric context varies. This is illustrated with three- and four-syllable transitive verb roots with all open syllables in order to optimize comparability of examples.

In the reducing three-syllable verb root akatz 'cut', (23a-d), the same syllabic structure in the unified representation /(C)V.CV.CV.CV(C)/ is shown to differ in syllabic structure at the phonetic level: $(23 \mathrm{a}, \mathrm{b})$ present reduction [CV.CV?.CV(C)], whereas (23c, d) do not [(C)V.CV.CV.CV(C)].

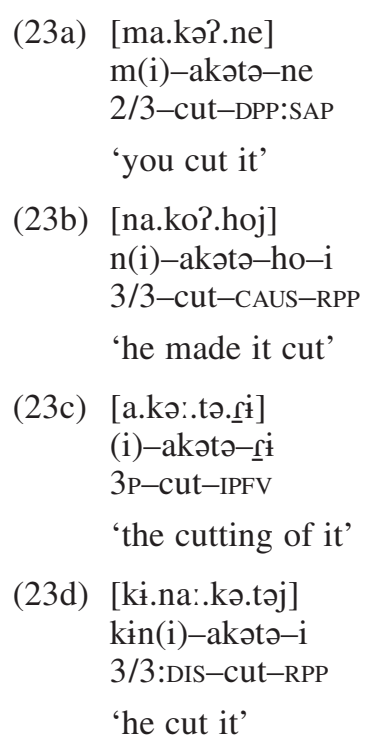

In examples with the same morphological context (-ne, -ho, - - $\dot{i},-i)$ but with an additional syllable in $(24 \mathrm{a}-\mathrm{c}) /(\mathrm{C}) \mathrm{V} . \mathrm{CV} . \mathrm{CV} . \mathrm{CV} . \mathrm{CV}(\mathrm{C}) /$ and one less syllable in (24d) /CV.CV.CVC/, the distribution of syllable reduction stays the same: $(24 a, b)$ reduce at the same morphological boundary [CV.CV.CV?. $\mathrm{CV}(\mathrm{C})]$, whereas $(24 \mathrm{c}, \mathrm{d})$ do not reduce [(V).CV.CV.CVC(V)].

(24a) [ma.na:.kə?.ne]
mən-akətə-ne

1/2-cut-DPP:SAP

'I cut you' 
(24b) [ki.na:.kə?.hoj]

kin-akətə-ho-i

3/3:DIS-cut-CAUS-RPP

'he made it cut'

(24c) [a.na:.kə.tə:..ị]

a-n-akətə-í

2-SHR-cut-NZR

'your cut one'

(24d) [na.kə:.təj]

n-akətə-i

3/3-cut-RPP

'he cut it'

With the same number of potential syllables - comparing $(24 a, b)$ with $(24 c$, d) - and same number of potential feet, syllabic structure at the surface level is different.

Same patterns emerge with a four-syllable verb root such as atihoti 'wash' in underlyingly five-syllable words in (25a-d), six-syllable words $(25 \mathrm{e}-\mathrm{g})$, and four-syllable words in $(25 \mathrm{~h})$.

(25a) [ma.ti:.hə?.ne]

m(i)-atihəti-ne

2/3-wash-DPP:SAP

'you washed it'

(25b) [na.ti:.ho?.hoj]

n(i)-atihəti-ho-i

3/3-wash-CAUS-RPP

He made it washed'

(25c) [a.ti:.hə.ti:.si]

(i) - atihəti- $\underline{\mathbf{s}} \mathbf{i}$

3P-wash-IPFV

'the washing of it'

(25d) [ki.na:.ti.hə:.tij] kin(i)-atihoti-i 3/3:DIS-wash-RPP

'he washed it'

(25e) [ma.na:.ti.hə?.ne] mən(i)-atihəti-ne 1/2-wash-DPP:SAP

'I washed you' 
(25f) [ki.na:.ti.hor.hoj]

kin(i)-atihəti-ho-i

3/3DIS-wash-CAUS-RPP

'He made it washed'

(25g) [a.na:.ti.hə:.ti..si]

a-n-atihoti- $\underline{-i}$

2-SHR-wash-NZR

'your washed one'

(25h) [na.tì..hə.tij]

$\mathrm{n}(\mathrm{i})-$ atihəti-i

3/3DIS-was-RPP

'he washed it'

The constant in these examples is the different sets of morphemes, not the syllablic structure of the suffix as had previously been described for other languages: some suffixes always condition syllable reduction (e.g., -ne, -ho, $-k \partial,-e,-a a k \partial)$ and some never do (e.g., $\left.-\underline{-} \dot{t},-i,-? \_a\right)$, and this happens no matter what the prosodic context is. Note again that these suffixes only condition syllable reduction if they combine with a reducing root. In the case of non-reducing three- and four-syllable roots, neither metrics nor morphology condition any kind of obligatory reduction. Examples (26) and (27) illustrate this with the suffixes $-n e$ and $-i$.

(26a) [ma.ho:.ho.ne]

m(i)-ahoho-ne

2/3-touch-DPP:SAP

'you touched it'

(26b) [ma.na:.ho.ho:.ne]

mən(i)-ahoho-ne

1/2-touch-DPP:SAP

'I touched you'

(26c) [na.ho:.ho.hoj]

n(i)-ahoho-ho-i

3/3-touch-CAUS-RPP

'he touched it'

(26d) [ki.na:.ho.ho:.hoj]

kin(i)-ahoho-ho-i

3/3:DIS-touch-CAUS-RPP

'he touched it' 


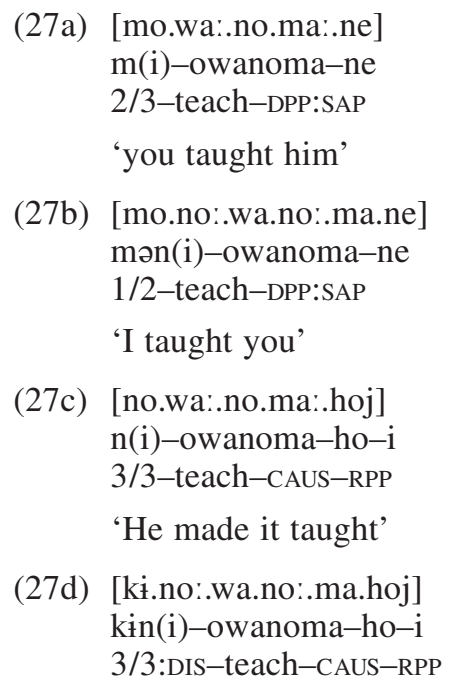

'He made it taught'

Unlike the Macushi phenomenon of iambic vowel deletion/reduction described by Hawkins (1950) and formalized by Kager (1997) and McCarthy (2008), what has been called syllable reduction in other Cariban languages is independent of metrics (although the reverse is not true since iambic foot construction is altered by syllable weight which syllable reduction adds at the morpheme boundary). There is, however, an additional optional fast speech phenomenon in the spontaneous corpus of Ye'kwana through which vowels in light syllables are reduced or deleted. The latter contrasts with syllable reduction in that it is not obligatory and it is not present in all registers. Although the primary sources for Macushi (Hawkins 1950; Abbott 1991) do not distinguish an independent and pervasive phenomenon of syllable reduction, examples given by Abbott (see table 4) also seem to show that syllable reduction can be identified independently of iambic deletion.

3. The problem of syllable reduction with vowel-initial suffixes. As was pointed out earlier, Gildea (1995) had noted vowels never conditioned syllable reduction. Yet in Ye'kwana there are ten suffixes that can be analyzed as vowel-initial and that condition reduction of the preceding syllable: -a 'non-past', -ahə 'participial nominalizer', -akə/-a?to 'third person distant past imperfective sg./pl.', -akene/-a?kene 'sAP distant past imperfective sg./ pl.', -anə/-anto 'recent past imperfective sg./pl.', -e 'participial adverbializer', - $e$ 'purpose of motion', - ehe 'simultaneous converb', - enhe 'potential adverbializer', -enhe 'recent adverbializer'. This section illustrates the morphophonological interactions with these suffixes then proposes a diachronic account of the different outcomes observed. 
3.1. Vowel initial suffixes with non-reducing roots. Before turning to syllable reduction in the context of /a/- and /e/-initial suffixes, I prove these are indeed vowel-initial by showing the morphophonemic interaction of these suffixes with non-reducing roots.

Following [a, i, i, u], both suffixes pattern the same way. They are simply added after a non-reducing [i] as shown in (28).

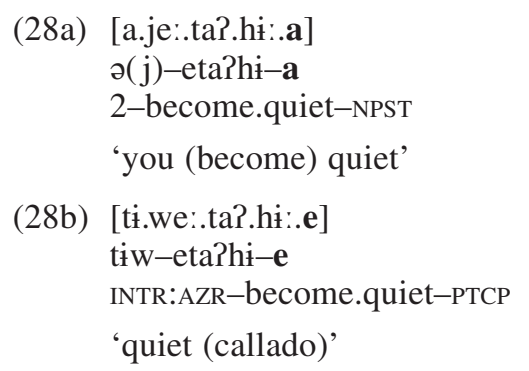

An epenthetic segment is inserted between the root and the suffix following $[i, u]$ :

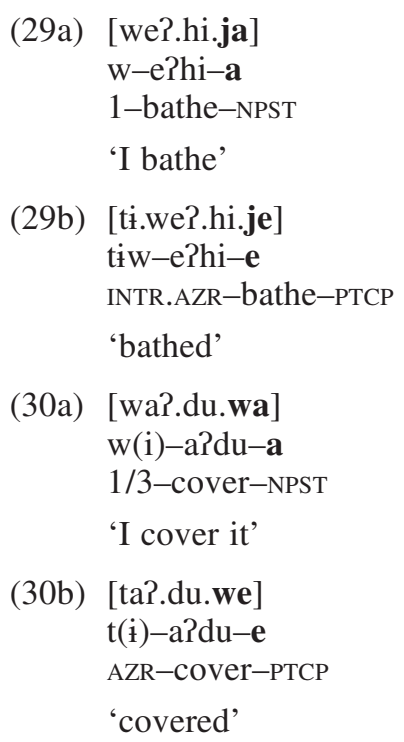

Following [a], the initial segment of these suffixes assimilates to it. ${ }^{10}$

\footnotetext{
10 This vowel cannot be realized with length when it is word final- that is, for the non-past suffix $-a$ as in [wo.ne:.ha] 'I try it' and the supine suffix $-e$ as in [o.ne:.ha] 'to go try it'. The vowel is clearly long when the suffix is bisyllabic or followed by another suffix-that is, by the $-m \dot{t}$ 'nominalizer' in the case of the participle.
} 
(31a) [o.ne:.ha.rit]

(i)-oneha- $\underline{\text { si }}$

3P-try-NZR

'the trying of it'

(31b) [o.ne:.haa.hə]

(i)-oneha-ahə

3P-try-ABS:NZR

'tried one'

(31c) [to.ne:.haa.mi]

$\mathrm{t}(\mathfrak{i})-$ oneha-e $-\mathrm{mi}$

AZR-try-PTCP-NZR

'one to be tried'

Following [e], /a/ is realized [a] and /e/ assimilates to the preceding vowel.

(32a) [nə?.me.a:.to]

n(i)-ə?me-a=to

3-fall.to.pieces-NPST $=$ PL

'They fall to pieces'

(32b) [ti.wว?.mee.mi]

tiw-2?me-e-mi

INTR:AZR-fall.to.pieces-PTCP-NZR

'one due to fall to pieces'

Following [ə, o], /a/ is realized [a] for bisyllabic roots with both open syllables, whereas /e/ assimilates to the preceding vowel.

(33a) [tว.nə:..̊i]

$\mathrm{t}-2 n \partial-\underline{\mathrm{s}} \mathrm{i}$

3P-eat.meat-NZR

'the eating of it'

(33b) [wว.nว:.a]

w(i)-ənว-a

1/3-eat.meat-NPST

'I eat it'

(33c) [tว.nəว.mi]

$\mathrm{t}(\mathrm{i})-\partial n \partial-\mathbf{e}-\mathrm{mi}$

AZR-eat.meat-PTCP-NZR

'one to be eaten'

Following $[\partial, 0]$ in all other root shapes, the preceding vowel assimilates to [a], while /e/ still assimilates to the preceding vowel. 


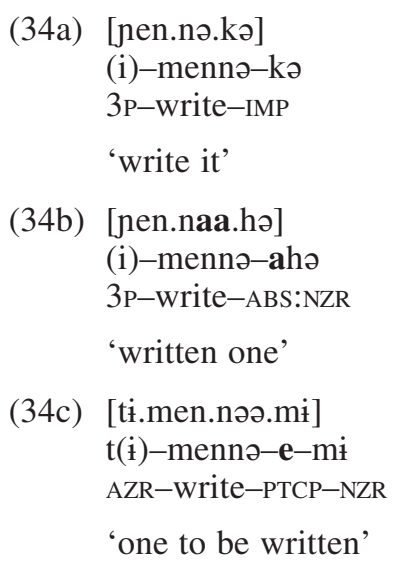

The epenthetic segment that is introduced in front of these suffixes and the different cases of assimilation help make the case for their analysis as vowelinitial morphemes.

3.2. Vowel initial suffixes with a variable initial consonant? In Ye'kwana, the suffixes listed in the introduction all condition syllable reduction. This fact is surprising as it is the only language in the Cariban family in which vowel-initial suffixes condition that process.

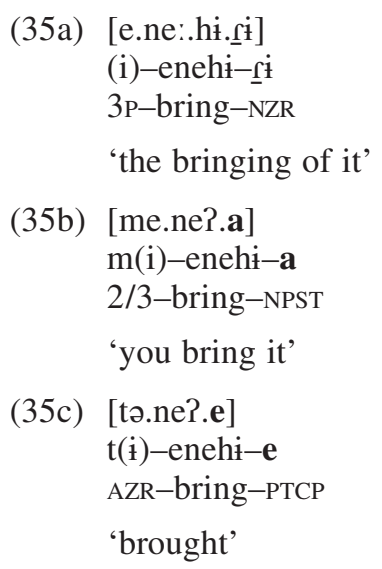

Gildea (1995) had argued that syllable reduction should not take place preceding a vowel because the vowel would create a heavy syllable (CV.CV+V>CV.CVV). However, (35) shows evidence of reduction and different syllabification (CV.CV $+\mathrm{V}>\mathrm{CV}$.CVC.V). Furthermore, patterns in contexts other than that of reducing $h \dot{t}$ and $t \dot{t}$ always present an extra consonantal segment between the reduced root and the vowel-initial suffixes. 
In some cases, the consonant preceding the initial vowel of the suffix resembles an epenthetic segment. This occurs when the nucleus of the preceding syllable is [i] or [u]:

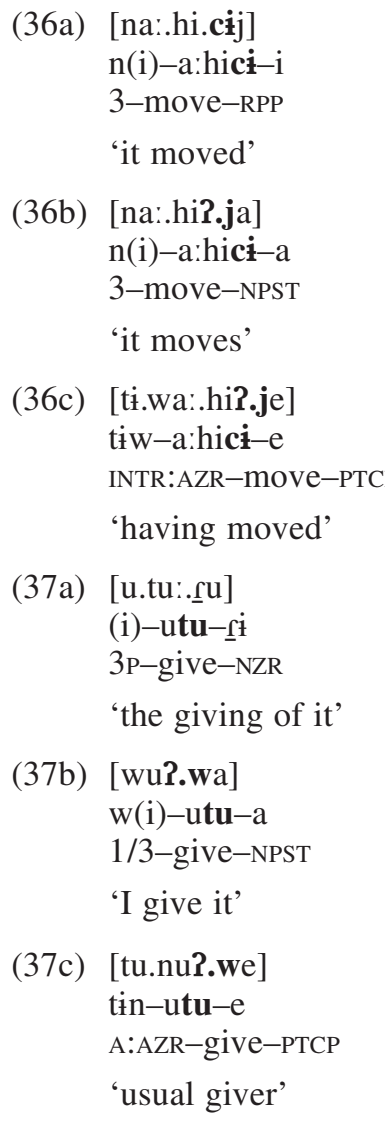

In this context, the preceding glottal stop is again not resyllabified with the initial vowel of the suffix. The nature of the epenthetic segment is however coherent with the pattern observed with non-reducing stems in (29-30).

In other cases, the consonant is a copy of the final consonant of the reduced stem. When the onset of the reducing syllable is /w/, this consonant is simply copied.

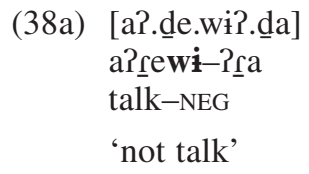


(38b) [nar.dew.wa]

n(i)-a?sewi-a

3-talk-NPST

'he talks'

(38c) [ti.war.dew.we]

tiw-a?sewi-e

INTR:AZR-talk-PTCP

'capable of talking'

In the case of nasals, however, the consonant is different than the original onset of the reduced syllable. In the absence of palatalization the consonant is $[\mathrm{y}]$.

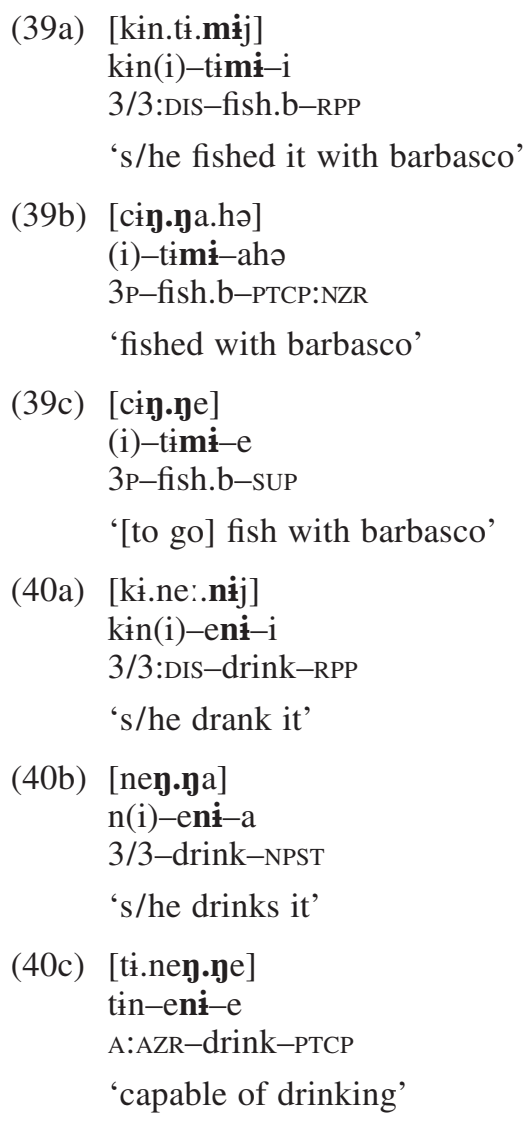

Here again, the new final consonant of the stem does not resyllabify with the initial vowel of the suffix, but the consonant copy is not inconsistent with 
the strategy seen in (36-37), where an epenthetic segment is introduced in onset position.

In (41-42), the consonant is identical to the original onset of the reduced syllable, but it cannot be analyzed as a copy of that consonant since the final syllable of the stem is a glottal stop.

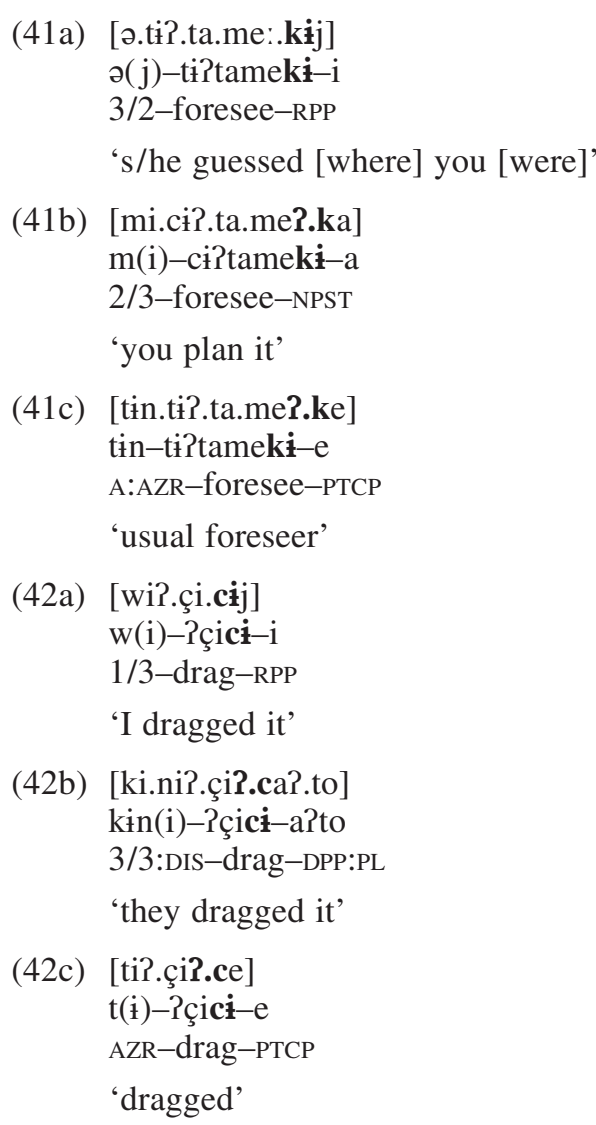

It could also be argued that metathesis took place, but this would mean, for example, that the glottal stop had to be in onset position of the suffix when the glottal stop is only attested elsewhere in coda position. However, as was pointed out in the introduction, examples in which the original consonant is /c/ present two different strategies: the one in (42), where it would seem the inserted consonant is a copy of the original onset, or the one in (36), where it would seem it is an epenthetic segment.

When observed from phonology in synchrony, the question raised by this kind of syllable reduction pattern in Ye'kwana is why there is, in most cases, an "extra" consonant in front of vowel-initial suffixes: is it a "deep," "abstract," 


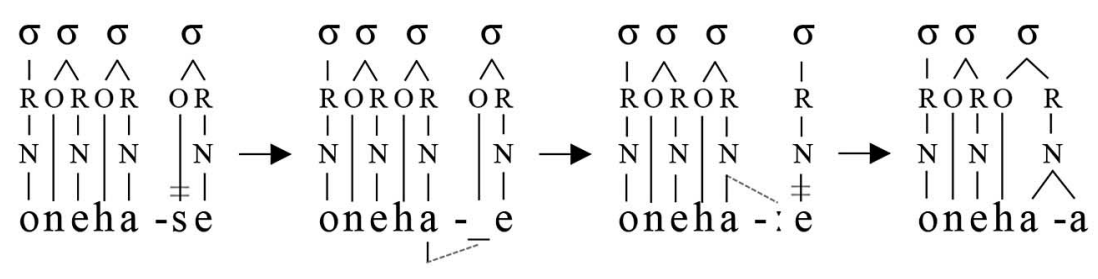

FIG. 3-*oneha $\rightarrow$ oneha.

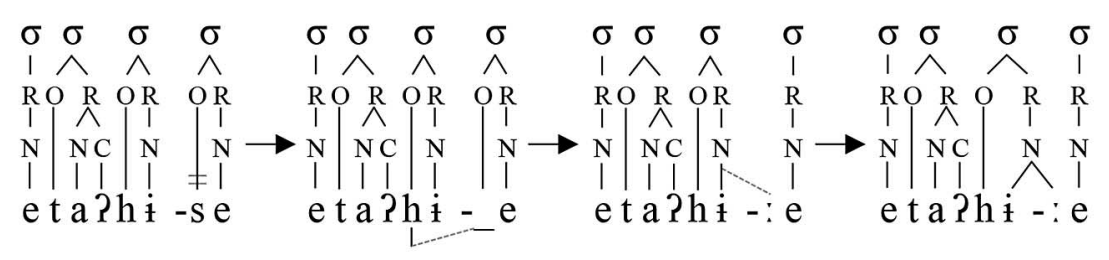

FIG. 4-*eta?hi $\rightarrow$ eta?hi.

or "ghost" consonant? However, by interpreting the facts from a comparative and historical point of view, taking into account that at least two of these suffixes reconstruct as consonant-initial ( $*_{-j a}$ 'non-past' and *-se 'participle'), one can conclude the Ye'kwana suffixes must have also contained an onset consonant. ${ }^{11}$ The evidence with reducing stems thus suggests that reduction occurred with consonant initial suffixes for which the consonant was lost, but traces of their original syllabic structure remained. This process is illustrated in the next section.

3.3. Reduction with $*_{-} \mathrm{Ce} / *_{-} \mathrm{Ca}$, reduced forms with -e/-a. I now present a possible diachronic picture of how it is that syllable reduction takes place with synchronically vowel-initial suffixes. All examples are shown with the suffix $-e$.

For a root where the final syllable is non-reducing, there is no alternation and the original initial consonant of the suffix was simply dropped. Vowel length is introduced in place of the original onset position. This is illustrated in figures 3 and 4 for the roots in (28) and (31), respectively. Where the final vowel was a high front or back vowel, instead of vowel length, a corresponding

\footnotetext{
11 Additionally, reconstruction of some lexical items shows evidence for loss of $*$ preceding $e$ in all contexts. For $* j$, however, cognates are rarer, and the only evidence so far of modification of the segment in Ye'kwana occurs in four cognates. In three of these, $* j$ precedes /a/, two immediately after a potentially reducing syllable: in these cases the synchronic reflex of $* j$ is $w$. There are only two cognates reconstructed as containing a syllable $w a$ in (Meira and Franchetto 2005), in both as the initial syllable. In this position *wa is preserved in Ye'kwana. There are as well several intervocalic wa in the collected Ye'kwana lexicon.
} 


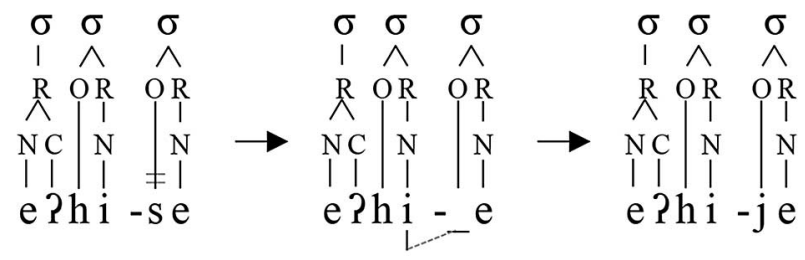

FIG. 5-*e?hi $\rightarrow$ e?hi.

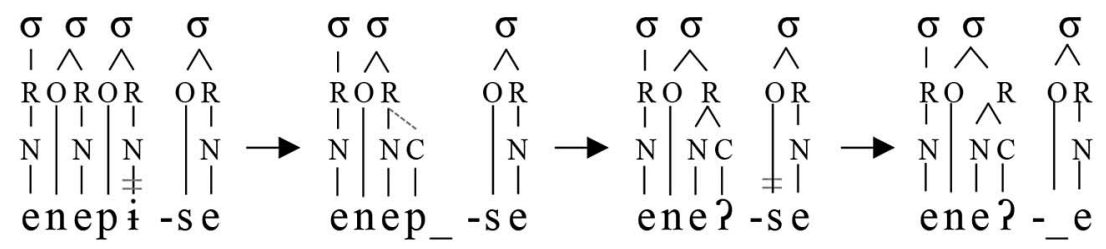

FIG. 6-*enepi- $\rightarrow$ enehi $\sim$ ene?.

epenthetic approximant palatal or labio-velar filled the original onset position of the suffix after the ellision of the initial consonant. This is illustrated in figure 5 for a root with a high front final vowel from (29).

For those roots for which the unreduced allomorph contains a glottal fricative as the onset alternating with a glottal stop as the final syllable of the reduced allomorph, a non-fricative variant of the syllable-initial consonant may have existed. In fact, Girard (1971) and Meira and Franchetto (2005) claim a $* p \rightarrow h$ change in Cariban, and Ye'kwana is one of the languages in which it is supposed to have happened. Taking this into account, syllable reduction must have preceded the $* p \rightarrow h$ sound change. ${ }^{12}$ The initial segment of the suffix was dropped at a later stage. Phonetically, in the reduced allomorph, the vowel preceding the glottal stop is laryngalized, which argues in favor of analyzing the glottal stop as the coda of the syllable preceding the suffix. This is illustrated in figure 6 for the root of (35).

Roots containing a velar segment as the onset of the last syllable in the unreduced allomorph did not debuccalize at the initial stage of syllable reduction. This allowed the coda of the reduced allomorph to spread to the onset position of the suffix as in the examples of figure 7 and figure 8. In the case of a root with a labio-velar aproximant as in figure 7, debuccalization never took place,

12 A change from a glottal fricative into a glottal stop is less likely than debuccalization of a stop into a glottal stop. The fricativization of $* p$ must have affected the unreduced allomorph of the root after syllable reduction was an established process. 


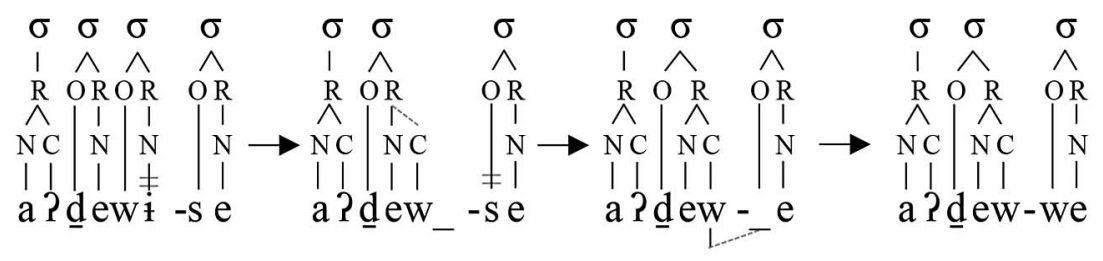

FIG. 7—*a?dewi $\rightarrow$ a?dewi $\sim$ a?dew.
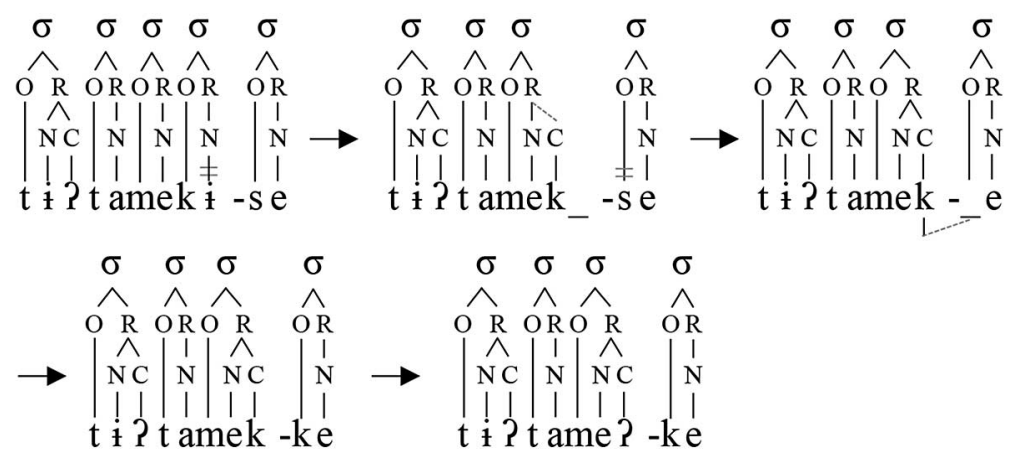

FIG. 8—*tîtameki $\rightarrow$ tî?tameki $\sim$ tìitame?.

probably because / $\mathrm{w} /$ is allowed in coda position even outside syllable reduction, unlike most of the other consonants (see 2.2.1). The outcome is different for $/ \mathrm{k} /$ : The velar stop in the unreduced allomorph of figure 8 alternates with a glottal stop-as evidenced by the phonetic laryngalization of the vowel that precedes it, which means that debuccalization did take place at a later stage.

Concerning the two different patterns of syllable reduction of a root containing the syllable $c \dot{t}$ in its unreduced form as pointed out for (36) and (42), the difference could be explained if palatalization took place at a later stage than syllable reduction.

In the context of syllable reduction with /e/ and /a/-initial suffixes, reducing syllables with a /t/ onset (from Proto-Cariban $* t$ ) follow the same pattern as syllables with a $/ \mathrm{h} /$ onset (from Proto-Cariban ${ }^{*} p$ ): debuccalization of the original onset with no spreading of the segment to the original onset position of the suffix, as illustrated in figure 8 . As /t/ and / $/$ / both palatalize to [c] following a high front vowel (see 2.2.1), roots containing the sequence [ic] word medially can never be realized with the original pre-palatalization consonant. However, in syllable reduction with an /e/-initial suffix, the synchronic realization of the original onset of the suffix as a palatal fricative suggests that 

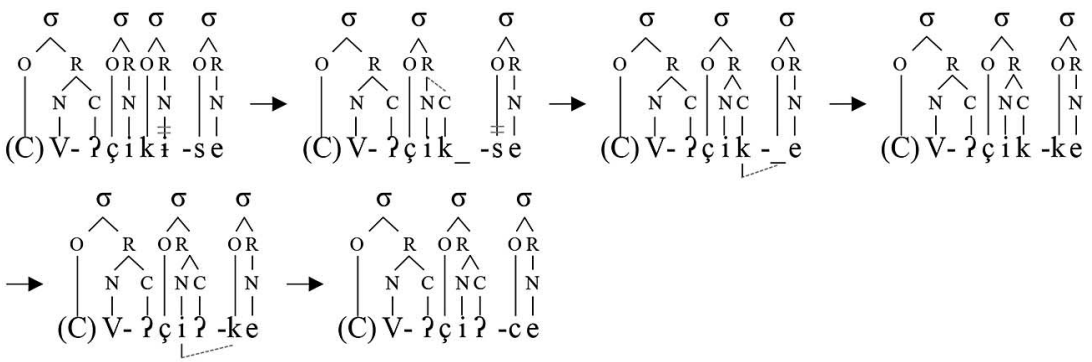

FIG. 9—*?çiki $\rightarrow$ Rçici Rçi?.

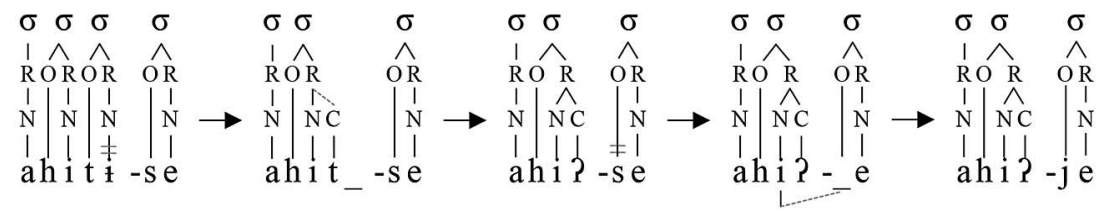

FIG. 10—*ahiti $\rightarrow$ ahici ahi?.

the pre-palatalization segment was velar. ${ }^{13}$ Thus, the root in (42) must have followed a similar diachronic pattern of syllable reduction than the root in figure 8 with a later palatalization as illustrated in figure 9 .

In contrast, roots for which the unreduced allomorph contains a palatal stop as the onset of the last syllable but no sign of the palatal stop in the reduced allomorph suggest an alveolar stop. Thus, the root in (36) followed a pattern like the root in figure 6 , with the additional step of introduction of an epenthetic segment $j$ corresponding to the nature of the high vowel /i/ in the last syllable of the reduced allomorph illustrated in figure 10.

Roots containing a nasal as the onset of the last syllable of the unreduced allomorph in alternation with an underspecified nasal segment in the reduced form are realized with a velar nasal when suffixed with /e/- and /a/-initial morphemes, independent of the nature of the original nasal segment. Explaining this realization is difficult with the proposed series of changes because, elsewhere, nasals in coda position share their place of articulation with the onset of the following syllable. Before the initial consonant of the suffix was dropped, the nasal should have assimilated to [s], but instead, the resulting nasal is velar. Support for interpreting the velar realization as the default for

${ }^{13}$ To add further support to this idea, one of the reviewers suggested cognates of the verb 'to drag' found in two other languages of the family: hpexekt 'pull' in Hixkaryana (Derbyshire 1979:197) and wi-hšiki- $\emptyset$ 'pull' in Waiwai (Hawkins 2015, entry 9-330-175-1). 


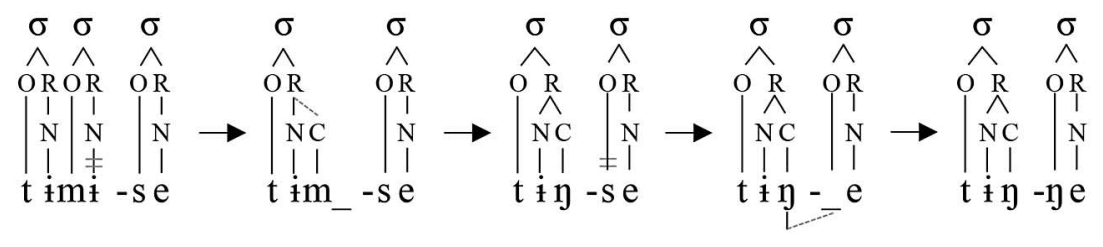

FIG. 11 - *timi $\rightarrow$ timi $\sim$ tin.

nasals in coda position comes from patterns in related languages: (i) wordfinal $/ \mathrm{n} /$ and $/ \mathrm{m} /$ assimilate to [ $\mathrm{\eta}$ ] in Panare, Makuchi, Akawaio, and Kari'nja (Spike Gildea, personal communication); (ii) sometimes reducing $/ \mathrm{m} /$ and /n/ assimilate to [n] in Panare (Gildea 1995:92); (iii) /m/ and /n/ assimilate to [ $\mathrm{y}$ ] both word-finally and also preceding the flap / $/$ in Macushi (Abbott 1991:142). Determining whether this is the same debuccalization as we have for non-nasals is beyond the scope of this paper. ${ }^{14}$ From this point, since the realization of the nasal could be expected to be velar when there are no place features to influence assimilation, even after debuccalization, the coda was able to spread to the onset position of the suffix. This is illustrated in figure 11 with the root from (39).

This section has shown that syllable reduction with vowel-initial suffixes is not easily explained in terms of one phonological process but that it is the result of the interaction of syllable reduction with a phonological process of consonant deletion at an earlier stage of the language. In synchrony, the different allomorphs of the vowel-initial suffixes are phonologically predictable but conditioned by morphology—instead of by phonology—as a partially productive alternation. The next section discusses the characteristics of a second "deviant" pattern of syllable reduction in Ye'kwana that adds to the fossilized flavor of this process.

4. Roots/stems where alternating syllables are reduced. Twelve verb roots in the available corpus-out of about 600 verb roots and stems-always present either the penultimate or the final syllable reduced; that is, these roots are never found with all of the syllables unreduced.

Some of the patterns of syllable reduction found elsewhere can be identified in the reduction process that applies to this set of roots. One characteristic the set shares is the fact that they almost all contain a nasal as the coda of

\footnotetext{
14 See De Lacy 2006:39-40 for an interesting proposal. He suggests that neutralization of nasals to a velar nasal in parallel to neutralization of non-nasals to a glottal stop indicates that in reality neutralization of nasals is also glottal but realized in the closest place of articulation as a velar nasal.
} 
the penultimate syllable in one allomorph and as the onset of the last syllable in the other allomorph. In (43-45), the roots in (a) and (b) all have the same number of syllables but the penultimate and last syllables do not have the same structure: the penultimate syllable is closed in (a) - by a nasal consonant - and the last syllable is open, whereas in (b) the situation is reversed.

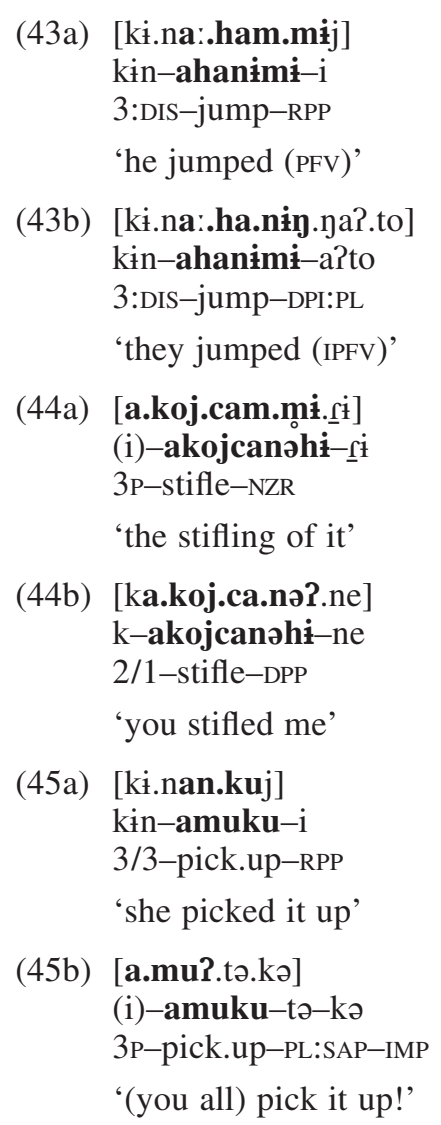

There are no forms of the verb where the two syllables are realized simultaneously in their full grade, meaning that there is no unreduced form of the root.

Other verb roots in the lexicon present a penultimate syllable closed by a / $/$ / or /N/ coda, followed by a potentially reducing syllable-a syllable containing a central vowel-but no alternation takes place. Some root examples are shown in (46a-e).

$\begin{array}{lll}\text { (46a) } & \text { e.mir.ci } & \text { 'hunt O with dogs' } \\ \text { (46b) e.ta?.hi } & \text { 'shut up' } \\ \text { (46c) } \text { P.mi } & \text { 'break O' } \\ \text { (46d) em.mi } & \text { 'spray the eyes of O' } \\ \text { (46e) } & \text { a.hən.tə } & \text { 'begin O' }\end{array}$


This shows that the alternation process illustrated in (43-45) is not as regular, since not all roots with the potential for alternation of reducing syllables exhibit the alternation. However, the roots where syllable reduction occurs on alternative syllables can be grouped according to the alternations they exhibit. These groupings are presented in the following subsections.

4.1. Reduction alternation in the last two syllables of a root. In the first group, the alternation takes place between $m m \dot{t}$ and $n \dot{t} N$ as in $(47 \mathrm{a}-\mathrm{e})$. The phonetic realization of the final nasal $N$ of the stem depends on the initial segment of the suffix.

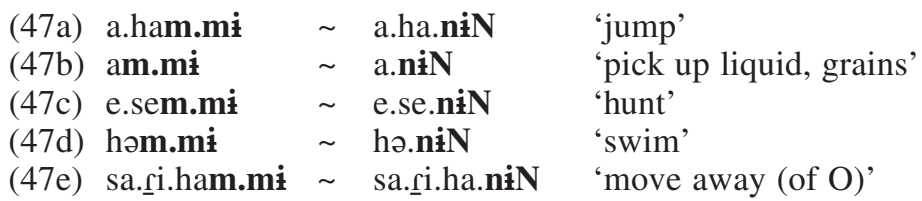

It seems that this group of stems all contained a syllable $n \dot{t}$ followed by a syllable $m \dot{t}$. An exploration of Meira's Cariban databases (unpublished data) reveals that there are a certain number of verb stems with possibly cognate endings in at least three languages of the family: three in Kari'nya (n.d.c), four in Tiriyó (n.d.d), and 15 in Hixkaryana (n.d.b). This fact suggests that the sequence nimi is some kind of suffix. Further investigations would be needed to confirm the status of nimi as an independent morpheme, in which case the syllable reduction alternation between $m m \dot{t}$ and $n \dot{t} N$ would not concern several verb roots, but a single morpheme.

The second group of verb roots presents an alternation between $m m i$ and $n ə ?$, as illustrated in (48a-e).

\begin{tabular}{|c|c|c|c|c|}
\hline & & $\sim$ & a.koj.ca.nə? & \\
\hline & e.ka & & e.ka.nə? & ieve $\mathrm{O}^{\prime}$ \\
\hline & e.se.nam.mi & & e.se.na.nə? & ‘finish O’ \\
\hline & on.tun.nam.mi & & on.tun.na.nə? & ‘suffer’ \\
\hline & se.re.nam.mi̊ & & se.e.na.nə? & 'dry O' \\
\hline
\end{tabular}

This alternation seems even more idiosyncratic in that the final syllable of the root has apparently a nasal onset [m] that reduces to a glottal stop [?] instead of a nasal, which contradicts the pattern described in the introduction. Happily, the devoiced nasal [m] is attested at morpheme boundaries as an allophone of $/ \mathrm{h} /$, and that would explain why the reduced form of what was apparently a nasal onset is not a nasal coda. We can conclude, then, that the unreduced form of the two final syllables was originally nəhi. In at least 11 other Cariban languages there is evidence of a causativizer morpheme that reconstructs to *nôpi (Gildea 2015). This means that in this group of roots the alternation is not inherent to the root but to a two-syllable morpheme. This would tend to support the analysis of a separate two-syllable morpheme in the preceding group. 
Even if it were confirmed that this alternation of reducing syllables is restricted to disyllabic suffixes, then one would have to ask why other originally disyllabic suffixes with one or both potentially reducing syllables do not present such alternation. There are three such suffixes in Ye'kwana containing a central vowel in each or one of their syllables: -hinit 'negative nominalizer',

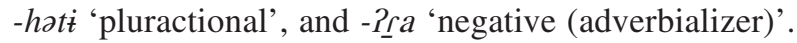

In the case of the first suffix, -hini always occurs word finally and the first syllable is never reduced. In the case of the second suffix, only the second syllable is ever reduced. The last suffix reconstructs to *pira, but in Ye'kwana there is never a trace of the unreduced first syllable. These three suffixes represent three different cases of historical stabilization of syllable reduction. In the first case the only potentially reducing syllable - the penultimate one-is never reduced and instead always causes reduction of the preceding syllable of the verb stem. In the second case, only the second syllable reduces and the first syllable always causes reduction of the preceding syllable of the verb stem. In the third case, the first syllable is always reduced-the second does not contain a reducing vowel-even in cases where the preceding syllable of the verb stem is also potentially reducing.

It is true that these suffixes do not share the characteristic of having a nasal as the onset of the first syllable such as -nimi and -nahi. However, nothing in the general pattern of syllable reduction indicates that syllables with nasal onsets should favor an unstable reduction-unstable in the sense that the alternation was not historically settled to either one of the syllables.

Surely, the morphosyntactic distribution of at least the three most frequent disyllabic suffixes can serve as an explanation of their different behavior visà-vis syllable reduction. This is just one more argument for describing syllable reduction not as a regular phonological process but rather as a historical process with some neat allomorphic patterns that can be captured with a few rules and a lot of idiosyncratic exceptions that must be learned independently. Now I turn to the last group of roots, for which all the syllables can alternatively reduce.

4.2. Reduction alternation for all syllables of a root. The first example is one disyllabic root (49a) that alternates between two reduced allomorphs: one where the first syllable is reduced (49b) and one where the second syllable is (49c, d). Example (49d) also shows that only one of the syllables is reduced at a time. The transitive participle with an /e/-initial suffix presents the same context for reduction of the first syllable as in (49b) and the same context of reduction for the second syllable as in (49c), but there is no alternation and the form of the participle is always tun-u?-we, with only the second syllable reduced.

(49a) [u.tu:.su]

(i) $-\mathbf{u t u}-\underline{\mathrm{r} u}$

3P-give-NZR

'the giving of it' 
(49b) [kun.tuj]

kin-utu-i

3DIS-give-RPP

'she gave it'

(49c) [wur.wa]

w(i)-utu-a

1/3-give-NPST

'I give it'

(49d) [tu.nu?.we]

tin-utu-e

A.AZR-give-PTCP

'usual giver'

The only other example of this group is what once was a trisyllabic root $\dot{i n} \dot{k} \dot{t}$, which can be reconstructed from the four different allomorphs it presents. Examples in (50) show the different forms of the root: $\dot{i} n \dot{t} ? \sim \dot{i} \eta k \dot{t} \sim n \dot{t} k \dot{t} \sim n \dot{t} ?$. A first glance at this set of variants might suggest a case of metathesis, but for each verb form below it can be demonstrated that it is all about syllable reduction of a root for which all three syllables were potentially reducing.

(50a) [i.ni?.ke]

iniki-e

sleep-SUP

'to go sleep'

(50b) [in.kî.da]

iniki-?da

sleep-NEG

'not sleep'

(50c) [ən.ni.ki ...ị]

$\partial(j)-w-\mathbf{i n i} \mathbf{i k}-\underline{\underline{I}} \mathbf{i}$

2-INTR-sleep-NZR

'your sleeping'

(50d) [tin.ni?.ke]

tiw-iniki-e

INTR.AZR-sleep-PTCP

'asleep'

The first allomorph seems to be the result of having only the third syllable of the root reduced. Indeed, the supine form of the verb - $e$ for intransitive verbs is only accompanied by a prefix $i$ - plus palatalization when the verb root is consonant-initial. For the supine form ini?ke, the first vowel $\dot{i}$ has then to be interpreted as the initial segment of the verb root. The nature of the original onset of the last syllable must have been velar, as hinted by the allomorph $k e$ 


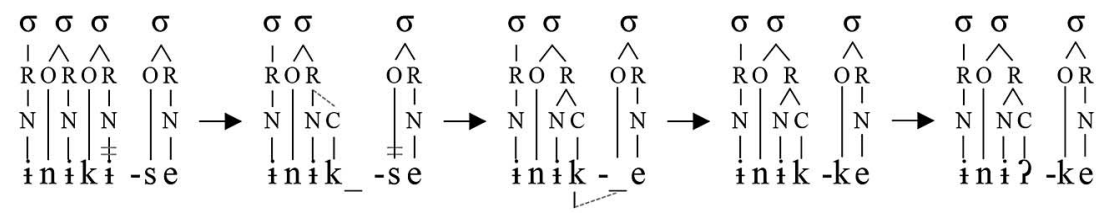

FIG. 12—*iniki $\rightarrow$ ini?.

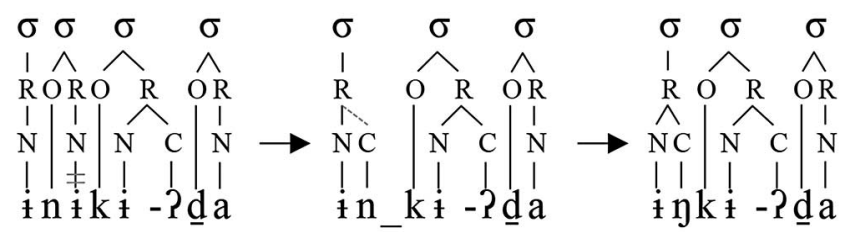

FIG. 13-*iniki $\rightarrow$ inki.

of the suffix (see figure 8). This is confirmed by the allomorphs of the root in $(50 \mathrm{~b}, \mathrm{c})$ for which the suffixes used never cause reduction of the last syllable of the verb stem. The last syllable of the original root was then $k \dot{k}$. Syllable reduction of the supine form in (50a) must have followed the same path of reduction as in figure 8 . This is illustrated in figure 12 . Only the last syllable of the verb reduces here: two consecutive syllables cannot be reduced since syllable structure must be $\mathrm{CV}$ for both the reducing syllable and the syllable that precedes it-syllable reduction obligatorily closes one of the syllables. Finally, an onset is needed for syllable reduction to take place, which is why the first onsetless syllable of the verb form is not reduced either.

The second allomorph seems to be the result of having only the mid syllable of the root reduced. Indeed, the negative suffix - $\underline{\underline{d}} \underline{\mathrm{d}} \mathrm{a}$ only presents a prefix in the same conditions as the supine and the first vowel $i$ has to be interpreted here as the initial segment of the verb root. As the suffix already brings a coda that closes the last syllable of the root, that last syllable cannot reduce. The initial syllable cannot reduce either because of the lack of an onset. The only syllable that has the possibility to reduce is the middle syllable $n \dot{t}$. The pattern for syllable reduction is illustrated in figure 13.

The third allomorph of the verb presents a different situation for syllable reduction of the root. The suffix following the last syllable never causes syllable reduction. This means that the middle syllable could be reduced, but the verb form presents the sequence $n i k i$, indicating that the middle syllable did not undergo syllable reduction. Here it is the first vowel of the verb that was reduced as the consonant of the preceding prefix provided an onset to 


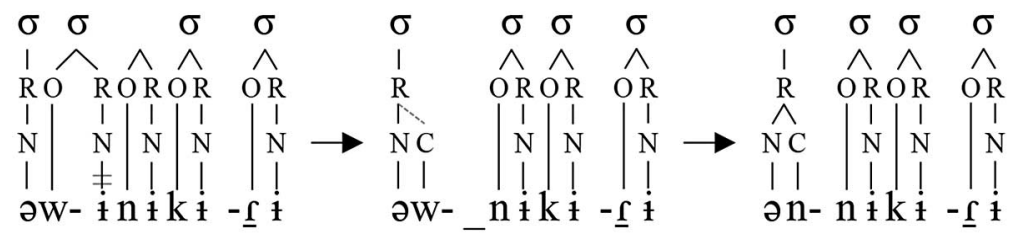

FIG. 14—*iniki $\rightarrow$ niki.
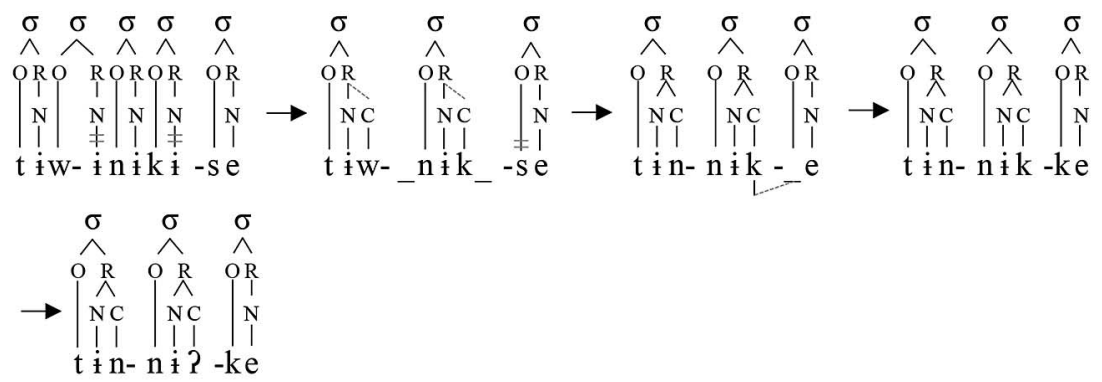

FIG. 15—*iniki $\rightarrow$ ni?.

form one syllable with it. From other vowel-initial intransitive verb roots, we know that the second person nominalized form of the verb with the suffix $-\underline{i} \dot{t}$ must be accompanied by the class marker for intransitives $w$ - (Cáceres and Gildea 2013). We can then conclude that the $n$ preceding the middle syllable of the root $n \dot{t}$ corresponds to an assimilation of the class marker to the nasal that follows it. The pattern of reduction for this verb form is illustrated in figure 14 .

It must be concluded from these first three example that when there was a choice between two adjacent syllables at the left edge of the root, syllable reduction operated in a symmetrical manner to what was observed at the right edge for the other two groups of alternating reducing syllables: if both an external and the adjacent internal syllable can be reduced, reduction of the external syllable takes priority, ultimately modifying the syllable structure around the other syllable in such a way that it cannot undergo reduction.

The remaining allomorph of the verb, $n \dot{t} ?$, presents only the middle syllable of the original root and this confirms the previous conclusion. On the right edge, the vowel-initial suffix - $e$ conditions reduction of the last syllable of the root. On the left edge, the final consonant of the intransitive participle prefix tiw- - where $w$ assimilates to the following nasal as in figure 14-allows the reduction of the first syllable of the root by providing an onset. Both external syllables reduce instead of just the internal syllable-reduction of $n \dot{t}$ would have prevented both adjacent syllables from reducing. This pattern of syllable reduction is illustrated in figure 15 . 
Three other roots could have presented the same alternative syllable reduction because all the syllables of the root exhibit the required features for reduction; however, they have only one or no reducing syllables. These are presented in (51).

$$
\begin{array}{lll}
\text { (51a) timi } & \sim \mathrm{tiN} & \text { 'fish with barbasco' } \\
\text { (51b) miki } \sim \mathrm{mi} \text { ? } & \text { 'transport' } \\
\text { (51c) } \mathrm{iki} & & \text { 'grate manioc' (non-reducing) }
\end{array}
$$

Frequency could be cited as an explanation for the difference between those roots that exhibit the alternation and those that do not, since 'sleep' and 'give' are arguably more frequent than lexical items describing more specific events - even if they are everyday events in the corresponding culture. However, contrary to what was observed with the two previous groups where the alternation concerns disyllabic suffixes, here it is the most frequent morphemes that preserved an alternation whereas less frequent lexical items present a non-alternating pattern of syllable reduction.

4.3. Intraspeaker syllable reduction alternation. One verb root presents different variants depending on the speaker. The variants of the verb 'to fall' all share the initial vowel and the last syllable of the root $e \underline{\imath} \underline{d} u k^{w} a$ $\sim e h u ? k^{w} a \sim e h e ? k^{w} a$. These variants look suspiciously similar to the alternating pattern of syllable reduction, but it seems that each speaker uses only one of them. In the following examples, counts are given for the form 's/he/it fell' from a pool of 20 speakers. ${ }^{15}$

(52a) [ne?.du.k $\left.{ }^{\mathrm{w}} \mathrm{aj}\right] 5$ speakers exclusively used variant (a)

$\left(52 b^{\prime}\right) \quad$ [ne.hu?.k $\left.{ }^{\mathrm{w}} \mathrm{aj}\right] 11$ speakers exclusively used variant $\left(\mathrm{b}^{\prime}\right)$

$\left(52 b^{\prime \prime}\right)$ [ne.he?.k $\left.{ }^{w} a j\right] 2$ speakers exclusively used variant $\left(b^{\prime \prime}\right)$ and $2\left(b^{\prime}\right)$ and $\left(b^{\prime \prime}\right)$

If we suppose the glottal stop in variant (52a) is the result of reduction of the second syllable $h u$ of $\left(52 b^{\prime}\right)$, it would also have to be claimed that the glottal stop in $\left(52 b^{\prime}\right)$ is the result of reduction of the second syllable $s u$ of (52a). ${ }^{16}$ Even though it was mentioned that syllables that presented the flap as their onset did not undergo syllable reduction (2.2.5), the roots for the verb 'to fall' in two other Cariban languages confirm that there are cognates to an original ehuruka root in Ye'kwana: /epuruka/ in Tiriyó and /ehurka/ in Hixkaryana. For this root then, the fact that a syllable containing the flap as

\footnotetext{
15 These data come from a study that was not aimed at eliciting responses for phonetic analyses, but the stimuli shown (the "Hierarchy Animation"; Cáceres 2016) contained scenes that prompted each of the speakers to use the form of the verb 'to fall' presented here more than once.

${ }^{16}$ The flap is realized as a corresponding stop word initially and after a glottal stop (/ $/$ / $\rightarrow[\underline{d}]$ / \#_, ?__ $)$.
} 
its onset appears reduced in one of its variants also points to an old case of reduction. In the third variant of the root the second vowel has assimilated to the first vowel but there is still rounding of the velar stop, which means that rounding was probably present before syllable reduction.

The variants of this verb and their consistent usage by different speakers are one more illustration of the no-longer purely phonological nature of some of the patterns of syllable reduction because they indicate the reduced forms of this root had to be learned by heart and not derived during production.

5. Final remarks. In its general form, when syllable reduction occurs for one syllable at a clearly identified morpheme boundary, the phenomenon could be described as a single synchronic phonological (or morphophonological) process. However, there are cases in Ye'kwana where a historical change might be confused with deep synchrony: it was demonstrated that at least one case that seemed to be explainable only as a "ghost" consonant could be in fact be better explained as a historical consonant, that divergent variants of a verb root may be understood as having a historical common form, and that a process that looks like metathesis may be the historical reduction of two identical vowels or consonant copy with subsequent debuccalization.

Gildea (1995) claimed that all the consonant clusters found in Cariban languages were the result of historical syllable reduction, and the Ye'kwana case of alternating syllable reduction provides further support. This pattern shows unambiguously non-morpheme-boundary syllables in their reduced and unreduced realizations.

Synchronically, syllable reduction is still an active process of morphophonological alternations at or near morpheme boundaries but, in a prior stage of the language, it was conceivably also an active process morpheme internally, creating word-internal consonant clusters and phonemic long vowels in a phonotactic system with only light syllables (cf. the limited set of consonants allowed as codas and the limited phonological distribution of the glottal in Ye'kwana).

It is particularly remarkable that syllable reduction is independent of the rhythmic pattern of vowel lengthening while, from the point of view of prosody, changes in syllable structure have a pervasive effect on the iambic pattern present in Ye'kwana.

The facts presented in this paper have shown that, when suspicious phonological mechanisms take place in a Cariban language, a comprehensive understanding is more effectively attained by gauging and describing the realm of the lexicon to which they apply and recognizing that some facts are better accounted for in a diachronic phonological analysis. 


\section{REFERENCES}

Аввотт, Miriam. 1991. Macushi. Handbook of Amazonian Languages Vol. 3, ed. Desmond C. Derbyshire and Geoffrey K. Pullum, 23-160. Berlin: Mouton de Gruyter.

AdAm, Lucien. 1893. Matériaux pour servir à l'établissement d'une grammaire comparée des dialectes de la famille Caribe. Bibliothèque Linguistique Américaine 17. Paris: J. Maisonneuve. Álvarez, José. 2003. Syllable reduction and mora preservation in Kari'ña. Amerindia 28:55-82.

- 2016. Esbozo de una gramática de la lengua Kari'ña (ms). <https://www.academia. edu/28516773/Esbozo_de_una_gramática_de_la_lengua_kari'ña>.

CÁceres, Natalia. 2007. Introduction à la langue des Ye'kwanas: Profil sociolinguistique et esquisse phonologique. MA thesis, Université Lyon 2.

. 2011. Grammaire fonctionnelle-typologique du Ye'kwana, langue Caribe du Venezuela. PhD dissertation, Université Lyon 2.

. 2016. Linguistic experimental methods in the Amazon: "The same" does not make "equal." Ms. in the author's possession.

Cáceres, Natalia, and Spike Gildea. 2013. La construcción imperfectiva del Ye'kwana (Caribe). Paper presented at the Sixth Conference on Indigenous Languages of Latin America (CILLA VI), University of Texas, Austin.

De Lacy, Paul. 2006. Markedness: Reduction and Preservation in Phonology. Cambridge: Cambridge University Press.

DerbyshiRe, Desmond C. 1979. Hixkaryana. Amsterdam: North-Holland.

ـ 1985. Hixkaryana and Linguistic Typology. Dallas: SIL and the University of Texas at Arlington.

Ferreira Alves, Ana Carolina, Sérgio Meira, and Spike Gildea. 2016. The creation of a fortislenis alternation in Akawaio, Bakairi and Arara (Cariban). Paper presented at Amazônicas VI, Universidad Nacional de Colombia en Amazonia, Leticia, Colombia, May 23-27.

GildeA, SpiKe. 1995. A comparative description of syllable reduction in the Cariban language family. IJAL 61(1):62-102.

. 2003. Proposing a new branch for the Cariban language family. Amerindia 28:7-32.

. 2012. Linguistic studies in the Cariban family. The Indigenous Languages of South America: A Comprehensive Guide, ed. Lyle Campbell and Verónica Grondona, 441-94. Berlin: Mouton de Gruyter.

- 2015. Comparative Cariban morphosyntax: Verb classes \& valence. Paper presented at Venezuelan Cariban: Working Conference on the Lexicon and Morphosyntax. Institut des Sciences de l'Homme (ISH), Lyon, France, May 13-14.

Girard, Victor. 1971. Proto-Carib phonology. PhD dissertation, University of California, Berkeley.

Hawkins, W. Neill. 1950. Patterns of vowel loss in Macushi (Carib). IJAL 16:87-90.

Hawkins, Robert E. 2015. Wai Wai dictionary. The Intercontinental Dictionary Series, ed. Mary Ritchie Key and Bernard Comrie. Leipzig: Max Planck Institute for Evolutionary Anthropology. Accessed on December 19, 2016, at http://ids.clld.org/contributions/175.

Hayes, Bruce. 1995. Metrical Stress Theory: Principles and Case Studies. Chicago: University of Chicago Press.

Hoff, Berend J. 1968. The Carib Language. Phonology, Morphonology, Morphology Texts and Word Index. The Hague: Martinus Nijhoff.

KAGER, ReNe. 1997. Rhythmic vowel deletion in optimality theory. Derivations and Constraints in Phonology, ed. Iggy Roca, 463-99. Oxford: Oxford University Press.

Koenn, Edward, and Sally Sharp Koenn. 1986. Apalai. Handbook of Amazonian Languages Vol. 1, ed. Desmond C. Derbyshire and Geoffrey K. Pullum, 33-127. Berlin: Mouton de Gruyter

Mattei-Muller, Marie Claude. 1981. La reducción silábica en Panare. Amerindia 6:59-84. 
McCarthy, John J. 2008. The serial interaction of stress and syncope. Natural Language \& Linguistic Theory 26(3):499-546.

Meira, SÉrgio. 1998. Rhythmic stress in Tiriyo (Cariban). IJAL 64(4):352-78.

1999. Syllable reduction and ghost syllables in Tiriyó. LACUS Forum 25:127-33.

. n.d.a Apalai Toolbox project with parsed and glossed texts and corresponding morpheme lexicon from published sources. Database in the author's possession.

- n.d.b Hixkaryana Toolbox project with parsed and glossed texts and corresponding morpheme lexicon from published sources. Database in the author's possession.

. n.d.c Kari'nya Toolbox project with parsed and glossed texts and corresponding morpheme lexicon from published sources. Database in the author's possession.

— n.d.d Tiriyó Toolbox project with parsed and glossed texts and corresponding morpheme lexicon from Sérgio Meira's own fieldwork. Database in the author's possession.

Meira, Sérgio, and Bruna Franchetto. 2005. The Southern Cariban languages and the Cariban family. IJAL 71:127-92.

Meira, SÉRgio, Spike GildeA, ANd B. J. Hoff. 2010. On the origin of ablaut in the Cariban family. IJAL 76:477-515.

Payne, Thomas E., And Doris L. Payne. 2013. A Typological Grammar of Panare. Leiden: Brill. WiLliams, JAMES. 1932. Grammar notes and vocabulary of the language of the Makuchi Indians of Guiana. St. Gabriel-Mödling, Austria: Verlag der Internationalen Zeitschrift Anthropos. 